NBER WORKING PAPER SERIES

\title{
INCOMPLETE MARKET DYNAMICS IN NEOCLASSICAL PRODUCTION ECONOMY
}

George-Marios Angeletos

Laurent-Emmanuel Calvet

Working Paper 11016

http://www.nber.org/papers/w11016

\author{
NATIONAL BUREAU OF ECONOMIC RESEARCH \\ 1050 Massachusetts Avenue \\ Cambridge, MA 02138 \\ December 2004
}

We received helpful comments from P. Aghion, A. Banerjee, R. Barro, J. Benhabib, R. Caballero, O. Galor, J. Geanakoplos, J.M. Grandmont, O. Hart, A. Kajii, H. Polemarchakis, K. Shell, R. Townsend, and seminar participants at Brown, Harvard, Maryland, MIT, NYU, Yale, and the 2004 GETA Conference at Keio University. The paper also benefited from excellent research assistance by Ricardo Reis. The views expressed herein are those of the author(s) and do not necessarily reflect the views of the National Bureau of Economic Research.

(C) 2004 by George-Marios Angeletos and Laurent-Emmanuel Calvet. All rights reserved. Short sections of text, not to exceed two paragraphs, may be quoted without explicit permission provided that full credit, including $($ ) notice, is given to the source. 
Incomplete Market Dynamics in a Neoclassical Production Economy

George-Marios Angeletos and Laurent-Emmanuel Calvet

NBER Working Paper No. 11016

December 2004

JEL No. D51, D52, D92, E20, E32

\section{ABSTRACT}

We investigate a neoclassical economy with heterogeneous agents, convex technologies and idiosyncratic production risk. Combined with precautionary savings, investment risk generates rich effects that do not arise in the presence of pure endowment risk. Under a finite horizon, multiple growth paths and endogenous fluctuations can exist even when agents are very patient. In infinitehorizon economies, multiple steady states may arise from the endogeneity of risktaking and interest rates instead of the usual wealth effects. Depending on the economy's parameters, the local dynamics around a steady state are locally unique, totally unstable or locally undetermined, and the equilibrium path can be attracted to a limit cycle. The model generates closed-form expressions for the equilibrium dynamics and easily extends to a variety of environments, including heterogeneous capital types and multiple sectors.

George -Marios Angeletos

Department of Economics

MIT

50 Memorial Drive, E51-251

Cambridge, MA 02142

and NBER

angelet@mit.edu

Laurent-Emmanuel Calvet

Department of Economics

Harvard University

Cambridge, MA 02138

and NBER

laurent_clavet@harvard.edu 


\section{Introduction}

How does incomplete risk-sharing affect the level and volatility of macroeconomic activity? We investigate this question in a neoclassical economy with missing markets and decentralized production. Idiosyncratic technological risks, unlike endowment shocks, introduce private risk premia on capital investment. The interaction of these premia with the precautionary motive can generate endogenous fluctuations and multiple equilibria even when agents are very patient, technology is strictly convex, and the wealth distribution has no effect on endogenous aggregates.

We conduct the analysis in the GEI growth framework introduced in Angeletos and Calvet (2003). Each agent is both a consumer and a producer, who can invest in a private neoclassical technology with diminishing returns to scale. In contrast to the traditional Ramsey model, individuals are exposed to idiosyncratic shocks in productive investment and possibly in some exogenous endowment. Agents also trade in financial markets. They can borrow or lend a risk-free bond, and partially hedge their idiosyncratic risks by exchanging a finite number of risky assets. All securities are real and there are no constraints on short sales. When markets are complete, the economy reduces to a Ramsey growth model with identical agents, as in Cass (1965), Koopmans (1965), and Brock and Mirman (1972). With missing markets, on the other hand, the economy cannot be described by a representative agent; explicit aggregation is nonetheless possible under a CARA-normal specification for preferences and risks.

We previously established two main results on macroeconomic performance in the neighborhood of complete markets. First, idiosyncratic production shocks, unlike endowment risk, tend to discourage investment. Thus in contrast to Bewley models (e.g. Aiyagari, 1994; Huggett, 1997; Krusell and Smith, 1998), incomplete risk-sharing can lead to lower steady state levels of capital and output than under complete markets. ${ }^{1}$ Second, financial incompleteness can increase the persistence of the business cycle. In the traditional Ramsey framework, a negative wealth shock has some persistence because agents seek to smooth consumption through time. When markets are incomplete, productive investment is risky and becomes even less attractive relative to current consumption. This can slow down convergence to the steady state, and thus increase the persistence of aggregate shocks.

The present paper extends our earlier work in a number of useful directions, including high levels of financial incompleteness and finite-horizon economies. We show that idiosyncratic production risk can generate rich dynamics that cannot be generated by endowment risks.

We begin by investigating finite-horizon economies. In contrast to the complete market Ramsey model, agents accumulate large precautionary wealth in later periods, because shocks received around the terminal date cannot be smoothed through time by borrowing and lending. In economies

\footnotetext{
${ }^{1}$ See Ljungqvist and Sargent (2000) for an excellent discussion of Bewley models.
} 
with large uninsurable risks, the anticipation of these movements lead to endogenous fluctuations along the entire equilibrium path.

The interaction between investment risk and precautionary savings can also generate nonmonotonicities in the equilibrium recursion. As a result, there exist multiple growth paths in some economies with investment risks.

We next examine infinite horizon economies. Multiple steady states can then arise from idiosyncratic production risks and the endogeneity of interest rates. Under incomplete markets, individual risk-taking is encouraged by the ability to self-insure against future consumption shocks, and thus by the anticipation of low borrowing rates in later periods. This property can generate multiple steady states in infinite horizon economies. In a rich equilibrium, a low real interest rate encourages a high level of risk-taking and investment, which in turn implies a low marginal productivity of capital and therefore a low interest rate. Conversely in a poor steady state or poverty trap, high real interest rates, high private risk premia and low investment are self-sustained. Poverty traps thus originate from the interaction between borrowing costs and risk-taking, a source of multiplicity that, to the best of our knowledge, is new to the literature. In contrast, earlier work has obtained poverty traps from wealth effects, building on the idea that poorer agents have lower ability to borrow and invest and may thus be trapped at low wealth levels (e.g., Banerjee and Newman, 1991; Galor and Zeira, 1993). We eliminate wealth effects by assuming CARA preferences, and highlight another channel through which financial incompleteness may affect the development of an economy: the impact of real interest rates on risk-taking.

The local dynamics around the steady state have a rich structure under incomplete markets. Depending on the economy's parameters, a steady state is locally unique, totally unstable or locally undetermined, and the equilibrium path can be attracted to a limit cycle. We observe that the complicated dynamics arise even when agents are very patient. This suggests that financial incompleteness may help mitigate the role of heavy discounting in neoclassical growth models of endogenous cycles (e.g. Boldrin and Montrucchio, 1986). ${ }^{2}$ For instance, Mitra (1996) and Nishimura and Yano (1996) prove that a period-three cycle only exists if the discount factor $\beta$ is less than the constant $[(\sqrt{5}-1) / 2]^{2} \approx 0.38$. By contrast, our GEI growth economy generates deterministic fluctuations with a Cobb-Douglas technology for large values of the discount factor, such as $\beta=0.95$.

We observe that like in finite horizon case, complicated dynamics arise even though technology is convex and there are no credit constraints. Our results thus complements earlier work examining how equilibrium multiplicity and endogenous cycles may originate from production non-convexities (e.g. Benhabib and Farmer, 1994), overlapping generations (Benhabib and Day, 1982; Grandmont,

\footnotetext{
${ }^{2}$ Note that it is possible to observe fluctuations in a multi-sector growth model for more patient agents (Benhabib and Nishimura, 1979).
} 
1985) or credit constraints (Galor and Zeira, 1993; Kiyotaki and Moore, 1997; Aghion, Banerjee and Piketty, 1999; Aghion, Bacchetta and Banerjee, 2000). The paper also extends the results obtained in the incomplete-markets endowment economy of Calvet (2001). Idiosyncratic production risks, unlike endowment risks, generate cycles even though storage and productive capital can be used as smoothing devices. They also induce novel dynamic effects, such a complementarity between future and current investment, and a negative feedback between future capital and current consumption.

Finally, we show that the tractability of our framework is preserved under a number of extensions. For instance, we introduce a storage technology with fixed positive returns, as well as randomness in the depreciation of productive capital. The model also generalizes to physical and human capital, and multiple sectors. Idiosyncratic production risks then also affect the allocation of savings across different types of capital or different sectors, thus introducing additional inefficiencies.

Section 2 presents the model. We solve the individual decision problem and calculate the equilibrium path under a finite horizon in Section 3. In Section 4 we investigate the infinite-horizon economy and examine the comparative statics and local dynamics of the steady state. Extensions to multiple capital types and sectors are considered in section 5. We conclude in Section 6. Unless stated otherwise, all proofs are given in the Appendix.

\section{The Model}

We consider a neoclassical growth economy with a finite number of heterogeneous agents, indexed by $h \in\{1, \ldots H\}$. Agents are born at date $t=0$, and live and consume a single good in dates $t \in\{0,1, . ., T\}$. The horizon is either finite $(T<\infty)$ or infinite $(T=\infty)$. The economy is stochastic and all random variables are defined on a probability space $(\Omega, \mathcal{F}, \mathbb{P})$.

\subsection{Production and Idiosyncratic Risks}

Each individual is an entrepreneur who owns his own stock of capital and operates his own production scheme. The technology is standard neoclassical, convex, and requires neither adjustment costs nor indivisibilities in investment. These assumptions would lead to the standard neoclassical growth model, if it were not for the following: production is subject to (partially undiversifiable) idiosyncratic uncertainty. An investment of $k_{t}^{h}$ units of capital at date $t$ yields

$$
y_{t+1}^{h}=A_{t+1}^{h} F\left(k_{t}^{h}\right)+\left(1-\delta_{t+1}^{h}\right) k_{t}^{h}
$$

units of the consumption good at date $t+1$. The production function $F$ is increasing, strictly concave, and satisfies the Inada conditions. ${ }^{3}$ The total factor productivity $A_{t+1}^{h}$ and the depreciation

\footnotetext{
${ }^{3}$ The function $F$ satisfies $F^{\prime}>0, F^{\prime \prime}<0, F(0)=0, F^{\prime}(0)=+\infty, F(+\infty)=+\infty$, and $F^{\prime}(+\infty)=0$.
} 
rate $\delta_{t+1}^{h}$ are random shocks specific to individual $h$, which introduce investment risk. They are the key ingredients of the model.

The productivity shocks $\left(A_{t+1}^{h}, \delta_{t+1}^{h}\right)$ allow us to capture the impact on growth of a wide range of technological risks. The uncertainty of an entrepreneurial project obviously influences specific investment in capital or R\&D. More generally, the riskiness of a worker's human capital affects a wide range of decisions such as labor supply, ${ }^{4}$ education, learning-by-doing, job search and career choices. As will be seen in Section 5, the model can be conveniently extended to explicitly include multiple sectors or the accumulation of human and physical capital.

For comparison purposes, we introduce two additional sources of income. First, individuals have access to a linear storage technology with gross rate of return $\rho \in[0,1]$. An investment of $s_{t}^{h}$ units of the good yields $\rho s_{t}^{h}$ with certainty at date $t+1$. Second, agents receive an exogenous stochastic endowment stream $\left\{e_{t}^{h}\right\}_{t=0}^{T}$. Income $e_{t+1}^{h}$ captures the effect of risks that are outside the control of individuals and do not affect production capabilities. Like productivity and depreciation, exogenous income $e_{t+1}^{h}$ is unknown at $t$ and revealed at $t+1$.

\subsection{Asset Structure and Preferences}

Individual risks can be partially hedged by trading a limited set of real securities. Each asset $n \in\{0, . ., N\}$ is short-lived: it is worth $\pi_{n, t}$ units of the good at date $t$, and yields $d_{n, t+1}$ units of the good at date $t+1$. Security $n=0$ is riskless and delivers $d_{0, t+1} \equiv 1$ with certainty next period. The quantity $R_{t} \equiv 1 / \pi_{0, t}$ denotes the gross interest rate between $t$ and $t+1$, and $r_{t}=R_{t}-1$ is the corresponding net rate. Assets are in zero net supply, there are no short-sale constraints, and default is not allowed. It is convenient to stack asset prices and payoffs into the vectors

$$
\pi_{t}=\left(\pi_{n, t}\right)_{n=0}^{N} \text { and } d_{t+1}=\left(d_{n, t+1}\right)_{n=0}^{N}
$$

Without loss of generality, we assume that $\left(d_{n, t+1}\right)_{n=0}^{N}$ is an orthonormal family of $L^{2}(\Omega)$, implying that risky assets have zero expected payoffs and are mutually uncorrelated.

At the outset of every period $t$, investors are informed of the realization of the asset payoffs $d_{t}$ and idiosyncratic shocks $\left\{\left(A_{t}^{h}, \delta_{t}^{h}, e_{t}^{h}\right)\right\}_{h=1}^{H}$. Information is thus symmetric across agents. ${ }^{5}$ Conditional on available information, agent $h$ selects a portfolio $\theta_{t}^{h}=\left(\theta_{n, t}^{h}\right)_{n=0}^{N}$ in period $t$.

We assume by construction that all the assets traded in one period are short-lived, in the sense that they only deliver payoffs in the next period. In the next sections, we will focus on equilibria with zero risk premia and deterministic interest rate sequences $\left\{R_{t}\right\}_{0 \leq t<T}$. For this reason, equilibrium

\footnotetext{
${ }^{4}$ See Marcet, Obiols-Homs and Weil (2000) for a recent discussion of the labor supply in a Bewley model.

${ }^{5}$ The results of this paper would not be modified under the weaker assumptions that income shocks are privately observed and the structure of the economy is common knowledge (provided of course that the financial structure remains exogenous).
} 
allocations and prices do not change if we introduce a perpetuity, namely a security delivering one unit of the good every period. ${ }^{6}$ The perpetuity is worth $\Pi_{t}=\sum_{s=t}^{T-1} 1 /\left(R_{t} \ldots R_{s}\right)$ at date $t$ after delivery of the period's coupon.

Each agent maximizes expected lifetime utility $U_{0}^{h}=\mathbb{E}_{0} \sum_{t=0}^{T} \beta^{t} u\left(c_{t}^{h}\right)$ subject in all date-events to the budget constraints

$$
\begin{aligned}
& c_{t}^{h}+k_{t}^{h}+s_{t}^{h}+\pi_{t} \cdot \theta_{t}^{h}=w_{t}^{h} \\
& w_{t+1}^{h}=e_{t+1}^{h}+A_{t+1}^{h} F\left(k_{t}^{h}\right)+\left(1-\delta_{t+1}^{h}\right) k_{t}^{h}+\rho s_{t}^{h}+d_{t+1} \cdot \theta_{t}^{h}
\end{aligned}
$$

The variable $w_{t}^{h}$, called wealth, represents the trader's net financial position at date $t$. When the horizon $T$ is finite, we use the convention that $s_{T}^{h}=0$ and $\theta_{T}^{h}=0$. Under an infinite horizon, we instead impose the transversality condition $\lim _{t \rightarrow \infty} \mathbb{E}_{0} \beta^{t} u\left(w_{t}^{h}\right)=0$.

\subsection{CARA-Normal Specification}

Agents have identical exponential utilities

$$
u(c)=-\frac{1}{\Gamma} \exp (-\Gamma c)
$$

where $\Gamma>0$ is the coefficient of absolute risk aversion. The asset payoffs $d_{t+1}$ and idiosyncratic shocks $\left\{\left(A_{t+1}^{h}, \delta_{t+1}^{h}, e_{t+1}^{h}\right)\right\}_{h}$ are jointly normal and independent of past information. There is thus no distinction between the conditional and unconditional distribution of these variables. The (unconditional) distribution of payoffs and shocks can vary through time, which in future applications may prove useful to capture the dynamic effect of financial innovation or business cycle variations in uninsurable risk (e.g. Mankiw, 1986; Constantinides and Duffie, 1996).

We obtain a tractable model when investment opportunities are symmetric across agents and idiosyncratic shocks cancel out in the aggregate. Specifically, we assume that the mean of idiosyncratic shocks is both constant and homogeneous across the population:

$$
A \equiv \mathbb{E} A_{t+1}^{h}>0, \quad \delta \equiv \mathbb{E} \delta_{t+1}^{h} \in[0,1], \quad e \equiv \mathbb{E} e_{t+1}^{h} \geq 0
$$

We rule out aggregate risk by imposing in every period the cross-sectional restriction:

$$
\frac{1}{H} \sum_{h=1}^{H}\left[\begin{array}{c}
A_{t+1}^{h} \\
\delta_{t+1}^{h} \\
e_{t+1}^{h}
\end{array}\right]=\left[\begin{array}{c}
A \\
\delta \\
e
\end{array}\right] .
$$

This assumption implies that the endogenous fluctuations observed in equilibrium will be unrelated to aggregate shocks.

\footnotetext{
${ }^{6}$ More generally, traders can dynamically replicate a large class of long-lived risky assets.
} 
Finally, we must guarantee that idiosyncratic risk is symmetrically distributed across the population. For all $h$, project the idiosyncratic risks on the asset span available at date $t$ :

$$
\begin{aligned}
A_{t+1}^{h} & =A+\sum_{n=1}^{N} \beta_{A, n}^{h, t} d_{n, t+1}+\widetilde{A}_{t+1}^{h}, \\
\delta_{t+1}^{h} & =\delta+\sum_{n=1}^{N} \beta_{\delta, n}^{h, t} d_{n, t+1}+\widetilde{\delta}_{t+1}^{h} \\
e_{t+1}^{h} & =e+\sum_{n=1}^{N} \beta_{e, n}^{h, t} d_{n, t+1}+\widetilde{e}_{t+1}^{h}
\end{aligned}
$$

The residuals $\left(\widetilde{A}_{t+1}^{h} ; \widetilde{\delta}_{t+1}^{h} ; \widetilde{e}_{t+1}^{h}\right)$ represent the undiversifiable component of the investment and endowment shocks to individual $h$. We assume that they are mutually uncorrelated:

$$
\left[\begin{array}{l}
\widetilde{A}_{t+1}^{h} \\
\widetilde{\delta}_{t+1}^{h} \\
\widetilde{e}_{t+1}^{h}
\end{array}\right] \sim \mathcal{N}\left(0,\left[\begin{array}{ccc}
\sigma_{A, t+1}^{2} & 0 & 0 \\
0 & \sigma_{\delta, t+1}^{2} & 0 \\
0 & 0 & \sigma_{e, t+1}^{2}
\end{array}\right]\right)
$$

and that the standard deviations $\sigma_{t+1}=\left(\sigma_{A, t+1} ; \sigma_{\delta, t+1} ; \sigma_{e, t+1}\right)$ are identical for all agents. The components of $\sigma_{t+1}$ represent useful measures of financial incompleteness, which can deterministically vary through time.

The CARA-normal specification will ensure that, given a deterministic price sequence, aggregate quantities are independent of the wealth distribution. This will overcome the curse of dimensionality that arises when the distribution of wealth - an infinite-dimensional object - enters the state space of the economy.

\subsection{Equilibrium}

Given a price sequence $\left\{\pi_{t}\right\}_{t=0}^{T}$, each agent chooses an adapted contingent plan $\left\{c_{t}^{h}, k_{t}^{h}, s_{t}^{h}, \theta_{t}^{h}, w_{t}^{h}\right\}_{t=0}^{T}$.

Definition. A GEI equilibrium consists of a price sequence $\left\{\pi_{t}\right\}_{t=0}^{T}$ and a collection of individual plans $\left(\left\{c_{t}^{h}, k_{t}^{h}, s_{t}^{h}, \theta_{t}^{h}, w_{t}^{h}\right\}_{t=0}^{T}\right)_{1 \leq h \leq H}$ such that:

(i) Given prices, each agent's plan is optimal.

(ii) Asset markets clear in every date-event: $\sum_{h=1}^{H} \theta_{t}^{h}=0$.

We make two immediate observations. First, if $R_{t}<\rho$, agents want to borrow an infinite amount at rate $R_{t}$ and invest it in the storage technology. The absence of arbitrage thus requires that $R_{t} \geq \rho$ in any date-event. Second, the absence of aggregate risk in the CARA-normal framework implies that deterministic price sequences $\left\{\pi_{t}\right\}_{t=0}^{T}$ can be obtained in equilibrium. We henceforth focus on price sequences satisfying these two conditions. 


\section{Equilibrium under a Finite Horizon}

\subsection{Decision Theory}

Consider an exogenous, deterministic path of asset prices $\left\{\pi_{t}\right\}_{t=0}^{T}$ satisfying the no-arbitrage condition $R_{t} \geq \rho$ in every period. We focus on a fixed agent $h$ and denote by $J^{h}(w, t)$ her indirect utility of wealth along the price path as of date $t$. Indirect utility satisfies the Bellman equation:

$$
J^{h}\left(w_{t}^{h}, t\right)=\max _{\left\{c_{t}^{h}, k_{t}^{h}, s_{t}^{h}, \theta_{t}^{h}\right\}} u(c)+\beta \mathbb{E}_{t} J^{h}\left(w_{t+1}^{h}, t+1\right)
$$

subject to the budget constraints (1) and (2). Since $J^{h}(w, T) \equiv u(w)$ at the terminal date, the value functions $J^{h}(., t)$ can be solved by a backward recursion.

The results are conveniently presented using

$$
\begin{aligned}
\Phi(k) & \equiv A F(k)+(1-\delta) k+e \\
G(k, a, \sigma) & \equiv \Phi(k)-\Gamma a\left[F(k)^{2} \sigma_{A}^{2}+k^{2} \sigma_{\delta}^{2}+\sigma_{e}^{2}\right] / 2 .
\end{aligned}
$$

The function $\Phi(k)$ denotes the expected non-financial wealth when investing $k$ units of capital. In contrast, $G(k, a, \sigma)$ is the risk-adjusted level of non-financial wealth corresponding to productive investment $k$, marginal propensity to consume next period $a$, and residual risks $\sigma=\left(\sigma_{A}, \sigma_{\delta}, \sigma_{e}\right)$.

Lemma 1 The value function belongs to the CARA class in every period:

$$
J^{h}(w, t)=-\left(\Gamma a_{t}\right)^{-1} \exp \left[-\Gamma\left(a_{t} w+b_{t}^{h}\right)\right] .
$$

The coefficients $a_{t}$ and $b_{t}^{h}$ are defined recursively by the terminal conditions $a_{T}=1, b_{T}^{h}=0$, and the equations

$$
\begin{aligned}
a_{t} & =\frac{1}{1+\left(a_{t+1} R_{t}\right)^{-1}}, \\
b_{t}^{h} & =a_{t}\left(M_{t}^{h}+\frac{b_{t+1}^{h}}{a_{t+1} R_{t}}\right),
\end{aligned}
$$

where

$$
M_{t}^{h}=\frac{G\left(k_{t}^{h}, a_{t+1}, \sigma_{t+1}\right)}{R_{t}}-k_{t}^{h}-\frac{\ln \left(\beta R_{t}\right)}{\Gamma a_{t+1} R_{t}}+\sum_{n=1}^{N} \pi_{n, t}\left[\beta_{e, n}^{h, t}+\beta_{A, n}^{h, t} F\left(k_{t}^{h}\right)-\beta_{\delta, n}^{h, t} k_{t}^{h}+\frac{R_{t} \pi_{n, t}}{2 \Gamma a_{t+1}}\right] .
$$

The optimal capital stock satisfies

$$
k_{t}^{h} \in \arg \max _{k \geq 0}\left\{G\left(k, a_{t+1}, \sigma_{t+1}\right)-R_{t} k+R_{t} \sum_{n=1}^{N} \pi_{n, t}\left[\beta_{A, n}^{h, t} F(k)-\beta_{\delta, n}^{h, t} k\right]\right\},
$$


and is strictly positive if $A+R_{t} \sum_{n=1}^{N} \pi_{n, t} \beta_{A, n}^{h, t}>0$. Individual consumption and portfolio choices are determined by

$$
\begin{aligned}
c_{t}^{h} & =a_{t} w_{t}^{h}+b_{t}^{h}, \\
\theta_{n, t}^{h} & =-\beta_{e, n}^{h, t}-\beta_{A, n}^{h, t} F\left(k_{t}^{h}\right)+\beta_{\delta, n}^{h, t} k_{t}^{h}-R_{t} \pi_{n, t} /\left(\Gamma a_{t+1}\right), \forall n \in\{1, \ldots, N\}, \\
\theta_{0, t}^{h}+\rho s_{t}^{h} & =\left(a_{t} / a_{t+1}\right) w_{t}^{h}-R_{t} b_{t}^{h}-R_{t} k_{t}^{h}-R_{t} \sum_{n=1}^{N} \pi_{n, t} \theta_{n, t}^{h} .
\end{aligned}
$$

The agent does not use the storage technology if $R_{t}>\rho$, and is indifferent between the bond and storage if $R_{t}=\rho$

Forward iteration of (3) implies that the marginal propensity to consume is inversely related to the price of perpetuity: $a_{t}=1 /\left(1+\Pi_{t}\right)$. The intercept $b_{t}^{h}$ decreases with the standard deviations of uninsurable risks $\sigma_{t+1}$, an implication of the precautionary motive for savings (Leland, 1968; Sandmo, 1970; Caballero, 1990). The demand for investment exhibits more novel features. The optimal capital stock decreases not only with productivity risks $\sigma_{A, t+1}$ and $\sigma_{\delta, t+1}$, but also with $a_{t+1}=1 /\left(1+\Pi_{t+1}\right)$ and therefore future interest rates $R_{s}(s \geq t+1)$. This property reflects the sensitivity of current risk-taking to the future cost of self-insurance.

\subsection{Equilibrium Characterization}

Let $C_{t}, W_{t}, K_{t}$, and $S_{t}$ denote the population average of consumption, wealth, capital and storage investment in a given date $t$. Initial wealth $\bar{W}_{0}=\sum_{h=1}^{H} w_{0}^{h} / H$ is an exogenous parameter of the economy.

Since idiosyncratic shocks cancel out in the aggregate, we focus on equilibrium paths with zero risk premia. ${ }^{7}$ Risky assets, whose expected payoffs are normalized to zero, therefore trade at zero prices: $\pi_{n, t}=0$ for all $n \in\{1, \ldots, N\}$. Condition (6) then reduces to

$$
k_{t}^{h} \in \arg \max _{k \geq 0}\left[G\left(k, a_{t+1}, \sigma_{t+1}\right)-R_{t} k\right] .
$$

Individual investment maximizes risk-adjusted output net of capital costs. Since all agents have the same marginal propensity to consume $a_{t}=1 /\left(1+\Pi_{t}\right)$ and the same objective function (8), the same capital stock can be chosen by all agents: $k_{t}^{h}=K_{t}$ for all $h$. We then aggregate across the population and obtain the equilibrium dynamics in closed form.

Proposition 1 The aggregate equilibrium dynamics are deterministic and risk premia on financial assets are equal to zero. All agents have identical marginal propensities to consume and choose

\footnotetext{
${ }^{7}$ As shown in the Appendix, the risk premium is necessarily zero in any equilibrium if the economy contains a single type of idiosyncratic investment risk (i.e., only productivity risk or only depreciation risk).
} 
identical levels of investment. Macroeconomic aggregates satisfy in every period the recursion

$$
\begin{gathered}
K_{t} \in \arg \max _{k \geq 0}\left[G\left(k, a_{t+1}, \sigma_{t+1}\right)-R_{t} k\right] . \\
W_{t+1}=\Phi\left(K_{t}\right)+\rho S_{t} \\
a_{t}=1 /\left[1+\left(a_{t+1} R_{t}\right)^{-1}\right] \\
C_{t+1}-C_{t}=\ln \left(\beta R_{t}\right) / \Gamma+\Gamma a_{t+1}^{2}\left[F\left(K_{t}\right)^{2} \sigma_{A, t+1}^{2}+K_{t}^{2} \sigma_{\delta, t+1}^{2}+\sigma_{e, t+1}^{2}\right] / 2 \\
W_{t}=C_{t}+K_{t}+S_{t}
\end{gathered}
$$

and the boundary conditions $W_{0}=\bar{W}_{0}, a_{T}=1$ and $K_{T}=0$.

While individuals are subjected to idiosyncratic shocks, macroeconomic quantities are deterministic functions of time. Nevertheless, the economy cannot be represented by a representative agent with consumption flow $\left\{C_{t}\right\}$, because equilibrium investment (6) and consumption growth (12) depend on idiosyncratic risk.

Mean consumption growth increases with the variance of future individual consumption, $\operatorname{Var}_{t}\left(c_{t+1}^{h}\right)$ $=a_{t+1}^{2}\left[F\left(K_{t}\right)^{2} \sigma_{A, t+1}^{2}+K_{t}^{2} \sigma_{\delta, t+1}^{2}+\sigma_{e, t+1}^{2}\right]$, which is a familiar consequence of the precautionary motive. The optimal capital stock, on the other hand, satisfies the FOC:

$$
R_{t}=1-\delta+A F^{\prime}\left(K_{t}\right)-\Gamma a_{t+1}\left[F\left(K_{t}\right) F^{\prime}\left(K_{t}\right) \sigma_{A, t+1}^{2}+K_{t} \sigma_{\delta, t+1}^{2}\right]
$$

In the absence of undiversifiable productivity risk $\left(\sigma_{A, t+1}=\sigma_{\delta, t+1}=0\right)$, the marginal product of capital is equated with the interest rate: $R_{t}=\Phi^{\prime}\left(K_{t}\right)=1-\delta+A F^{\prime}\left(K_{t}\right)$. This relation, which is well-known in complete market models, holds more generally in the presence of uninsurable endowment shocks $\left(\sigma_{e, t+1} \geq 0\right)$. But when production risks cannot be fully hedged $\left(\sigma_{A, t+1}\right.$ or $\left.\sigma_{\delta, t+1}>0\right)$, the interest rate is equal to the risk-adjusted return to capital $G_{k}\left(K_{t}, a_{t+1}, \sigma_{t+1}\right)$. The difference $\Phi^{\prime}\left(K_{t}\right)-R_{t}=\Gamma a_{t+1}\left[F\left(K_{t}\right) F^{\prime}\left(K_{t}\right) \sigma_{A, t+1}^{2}+K_{t} \sigma_{\delta, t+1}^{2}\right]$ represents a private risk premium on investment. Note that it does not include the endowment coefficient $\sigma_{e, t+1}$. Under idiosyncratic production shocks, risk aversion thus induces the sensitivity of current investment $K_{t}$ to future marginal propensity $a_{t+1}=1 /\left(1+\Pi_{t+1}\right)$, and thus to future interest rates. When high real rates are anticipated in the near future, agents know that it will be costly to smooth adverse future productivity shocks by borrowing. The anticipation of a high marginal propensity $a_{t+1}$ then implies low productive investment in the current period.

Idiosyncratic production risk, unlike endowment risk, thus implies that current investment is sensitive to future interest rates. This effect introduces a dynamic complementarity in general equilibrium. The anticipation of low income, low savings, and high real interest rates in future periods discourages current risk-taking and investment, which in turn imply low income and high real interest rates in the future. The expectation of low economic activity is thus partly or fully 
self-fulfilling. In Angeletos and Calvet (2003), we highlighted how this positive feedback between future and current investment can increase the persistence of the transitional dynamics. We will see below that this complementarity, coupled with the precautionary motive, may also generate multiple growth paths and steady states.

We finally note that although the production function $F(k)$ is strictly concave, the risk-adjusted output $G(k, a, \sigma)$ need not be concave in $k$ when $\sigma_{A}>0$. The function $G$, however, is single-peaked under the following condition.

Assumption 1 One of the following conditions holds: (i) The function $F(k)^{2}$ is strictly convex; (ii) There is no idiosyncratic depreciation risk and $\rho \geq 1-\delta$.

We then easily show

Lemma 2 The optimal capital stock $k_{t}^{h}$ is the unique solution to FOC condition (14).

\subsection{Equilibrium Analysis}

Equilibrium paths can be calculated by a backward recursion. To simplify the discussion, we now specialize to a stationary economy, in which residual standard deviations are constant through time: $\sigma_{t}=\left(\sigma_{A}, \sigma_{\delta}, \sigma_{e}\right)$ for all $t$. Consider the macroeconomic vector $x_{t}=\left(a_{t}, C_{t}, W_{t}, K_{t}, S_{t}, R_{t}\right)$ and the reduced vector $z_{t}=\left(a_{t}, C_{t}, W_{t}\right)$. We easily show

Lemma 3 For any $z_{t+1} \in(0,1] \times \mathbb{R} \times[e,+\infty)$, there exists a unique macroeconomic vector $x_{t} \in$ $(0,1) \times \mathbb{R}^{2} \times \mathbb{R}_{+}^{3}$ satisfying the equilibrium recursion $(9)-(13)$.

This property defines the mappings $x_{t}=\widetilde{H}\left(z_{t+1}\right)$ and

$$
z_{t}=H\left(z_{t+1}\right)
$$

The equilibrium dynamics are thus fully characterized by the three-dimensional vector $z_{t}{ }^{8}$

The equilibrium calculation is similar to the method used for the complete-market Ramsey model. At terminal date $T$, individuals consume all their wealth, which implies the terminal conditions $a_{T}=1$ and $C_{T}=W_{T}$. The initial wealth level provides the third boundary condition: $W_{0}=\bar{W}_{0}$. For any choice of $W_{T} \in[e,+\infty)$, we can define $z_{T}=\left(1, W_{T}, W_{T}\right)$ and recursively calculate the path $z_{t}=H\left(z_{t+1}\right)$. Note that the condition $W_{t+1} \in[e,+\infty)$ does not guarantee that $W_{t} \in[e,+\infty)$. Some terminal wealth levels imply that $W_{t}<e$ and the algorithm stops at some instant $t>0$. Other values $W_{T}$ generate an entire path $\left\{z_{t}\right\}_{t=0}^{T}$, leading to initial wealth level

\footnotetext{
${ }^{8}$ The dimensionality of the equilibrium dynamics is determined by the financial structure and the productivity of capital. More specifically, our model reduces to: a two-dimensional system in $\left(C_{t}, W_{t}\right)$ when $A>0$ and markets are complete; a one-dimensional system in $a_{t}$ when agents do not produce $\left(A=0, \delta=1, \rho=0, \sigma_{A}=\sigma_{\delta}=0\right)$.
} 
$W_{0}$. The recursion thus defines a function $W_{0}\left(W_{T}\right)$, whose domain is a subset of $[e,+\infty)$. Since the initial wealth $\bar{W}_{0}$ is exogenous, an equilibrium corresponds to a terminal wealth level $W_{T}$ such that $W_{0}\left(W_{T}\right)=\bar{W}_{0}$.

In the Appendix, we extend the function $W_{0}(\cdot)$ to a continuous mapping defined on $[e, \infty)$, and examine its behavior when $W_{T} \rightarrow e$ and $W_{T} \rightarrow+\infty$. It is then easy to prove that $W_{0}\left(W_{T}\right)=\bar{W}_{0}$ admits at least one solution for any $\bar{W}_{0}$.

Proposition 2 There exists an equilibrium in any finite-horizon economy.

We now investigate the properties of equilibrium paths.

\subsection{Finite-Horizon Growth Paths}

When uninsurable risks are relatively small, we may expect that the GEI equilibrium remains close to the complete-market growth path. In fact, the GEI growth path combines two features: a turnpike property and a strong precautionary effect around the terminal date, as illustrated in Figure $1 A .{ }^{9}$ Starting from a low capital stock, the economy accumulates wealth and remains many periods in the neighborhood of the GEI steady state. ${ }^{10}$ This is evident in Figure $1 B$, which plots equilibrium wealth normalized to its steady-state level. In the traditional Ramsey model, aggregate wealth progressively decreases around the terminal date $T$. Under incomplete markets, however, individuals have a very strong precautionary motive in later periods, because shocks around $T$ cannot be easily smoothed by borrowing and lending. As a result, aggregate wealth overshoots the steady state before being consumed in the very last periods. Note that the large accumulation of wealth is financed by a reduction of consumption and an increase in productive investment some periods before the terminal date. These results thus contrast with finite-horizon complete market dynamics, in which the capital stock never exceeds its steady-state level in an initially poor economy.

When markets are very incomplete, the growth paths of the economy can be startlingly different than in the traditional Ramsey model. The differences originate in nonmonotonicities embedded in the equilibrium recursion. Consider for instance the impact of a higher future wealth level $W_{t+1}$ in the absence of storage. ${ }^{11}$ Higher wealth next period requires higher current investment $K_{t}=\Phi^{-1}\left(W_{t+1}\right)$ and a lower interest rate $R_{t}$, leading to an increase in the component $-\ln \left(\beta R_{t}\right) / \Gamma$ of current consumption:

$$
C_{t}=C_{t+1}-\ln \left(\beta R_{t}\right) / \Gamma-\Gamma a_{t+1}^{2}\left[F\left(K_{t}\right)^{2} \sigma_{A}^{2}+K_{t}^{2} \sigma_{\delta}^{2}+\sigma_{e}^{2}\right] / 2 .
$$

\footnotetext{
${ }^{9}$ The economy in Figure 1 is specified by the Cobb-Douglas production function $F(k)=k^{\alpha}$ and the parameters $\Gamma=10, A=1, \alpha=0.4, \beta=0.95, \delta=0.05, \rho=1-\delta, e=0, \sigma_{A}=0.5, \sigma_{\delta}=0, \sigma_{e}=0, T=1000$.

${ }^{10}$ We discuss the steady state of the infinite-horizon economy in the next section.

${ }^{11}$ The analysis corresponds to the case $W_{t+1}<W_{t+1}^{*}$, as defined in the proof of Lemma 3 .
} 
Under complete markets, this is the only effect. Current consumption $C_{t}$ and wealth $W_{t}=C_{t}+K_{t}$ are increasing functions of future wealth $W_{t+1}$. The function $W_{0}(\cdot)$ monotonically increases in $W_{T}$ and there exists a unique equilibrium growth path. More generally, we show in the Appendix that the monotonicity of $W_{0}(\cdot)$ and thus equilibrium uniqueness also hold in economies with only endowment shocks $\left(\sigma_{e} \geq 0, \sigma_{A}=\sigma_{\delta}=0\right)$.

With uninsurable production risks, however, the equilibrium recursion need not be monotonic. High output next period requires a high level of capital investment $K_{t}$ and therefore high individual risk-taking in the current period. Agents then have a strong precautionary motive, which implies a large risk adjustment $F\left(K_{t}\right)^{2} \sigma_{A}^{2}+K_{t}^{2} \sigma_{\delta}^{2}$ and a possible reduction of current consumption in equation (16). As a result, consumption $C_{t}$ and wealth $W_{t}=C_{t}+K_{t}$ can be decreasing functions of future wealth $W_{t+1}$. The anticipation of high wealth in the future may thus imply a precautionary reduction in current consumption and wealth. In other words, the interaction of investment risk with the precautionary motive can generate a negative feedback between future and current wealth.

The non-monotonicities generated by productivity shocks have two possible implications: multiple equilibria and complicated dynamics, which we successively examine.

Proposition 3 There robustly exist multiple equilibrium paths in some finite-horizon economies with idiosyncratic production risks. In contrast, equilibrium is unique in any economy with either complete markets or only endowment risks.

Figure 2 illustrates the function $W_{0}\left(W_{T}\right)$ for appropriate values of the economy's parameters. ${ }^{12}$ Given an initial wealth level $\bar{W}_{0}$, agents can coordinate on several paths. For instance, they can choose a high level of risky investment, and low consumption for precautionary reasons. Conversely, they can coordinate on low investment, which is matched by weak precautionary savings and high consumption. Under uninsurable production risks, two economies with identical technologies, preferences and financial structures can thus coordinate on different paths of capital accumulation, savings and interest rates.

Complicated dynamics can also arise. To simplify the discussion, we consider an economy with a single equilibrium. The unique growth path illustrated in Figure 3 displays large endogenous fluctuations. The graph illustrates the kind of complex dynamics that the introduction of incomplete markets may generate in an otherwise standard neoclassical economy. Such behaviors do not necessarily require a high degree of impatience. For instance in Figure 3, we obtain endogenous fluctuations along the unique equilibrium path with a high discount factor $(\beta=0.99)$ and a low rate of capital depreciation $(\delta=0.1) \cdot{ }^{13}$ Large undiversifiable production risk thus generates endogenous

\footnotetext{
${ }^{12}$ The economy in Figure 2 is specified by the Cobb-Douglas production function $F(k)=k^{\alpha}$ and the parameters $\Gamma=10, A=10, \alpha=0.35, \beta=0.9, \delta=0.5, \rho=1-\delta, e=0, \sigma_{A}=100, \sigma_{\delta}=0, \sigma_{e}=0, T=40$.

${ }^{13}$ We also assume in Figure 3 that $\Gamma=1.625, A=10, \alpha=0.55, \rho=0.3, e=0, \sigma_{A}=50, \sigma_{\delta}=0, \sigma_{e}=0, T=50$.
} 
fluctuations with more patient agents than in earlier models considered in the literature. We also observe in Figure 3 that the interest rate frequently reaches the lower bound imposed by the storage technology. Thus, storage does not preclude the existence of endogenous fluctuations, but dampens variations in the interest rate and macroeconomic aggregates.

Overall, the analysis of the finite-horizon economy illustrates the strong distinction between idiosyncratic endowment and productivity shocks. When investors receive only endowment shocks, the equilibrium recursion is monotonic and there exists a unique growth path. On the other hand, the presence of undiversifiable productivity shocks generates non-monotonicities, multiple equilibria and endogenous cycles. Note, however, that large idiosyncratic risks seem to be required for such complicated dynamics. This suggests that when building macroeconomic models, investment risk should probably be used in combination with traditional sources of endogenous fluctuations.

\section{Equilibrium with Infinite Horizon}

\subsection{Decision Theory and Equilibrium}

Given a deterministic sequence of asset prices $\left\{\pi_{t}\right\}_{t=0}^{+\infty}$, we calculate the optimal decision of an individual investor $h$ by taking the pointwise limit of the finite horizon problem. Specifically in every period, let $\Pi_{t}=\sum_{s=t+1}^{+\infty} 1 /\left(R_{t} . . R_{s-1}\right)$ denote the exogenous price of a perpetuity and $a_{t}=\left(1+\Pi_{t}\right)^{-1}$ the implied marginal propensity to consume. We also consider the solution $k_{t}^{h}$ to equation (14), the variables $M_{t}^{h}$ defined by (5), and

$$
b_{t}^{h}=a_{t}\left(M_{t}^{h}+\sum_{s=t+1}^{+\infty} \frac{M_{s}^{h}}{R_{t} \ldots R_{s-1}}\right) .
$$

The convergence of the series $a_{t}$ and $b_{t}^{h}$ is guaranteed by the following sufficient conditions:

Assumption 2. The sequences $\left\{\pi_{t}\right\}_{t=0}^{+\infty},\left\{R_{t}\right\}_{t=0}^{+\infty}$ and $\left\{\Pi_{t}\right\}_{t=0}^{+\infty}$ are bounded.

We can then show

Lemma 4 Under Assumption [2], the value function belongs to the CARA class every period: $J^{h}(W, t)=-\left(\Gamma a_{t}\right)^{-1} \exp \left[-\Gamma\left(a_{t} W+b_{t}^{h}\right)\right]$, and the consumption-portfolio decision satisfies (7).

Since the optimal decision is the limit of the finite horizon problem, Ponzi schemes are ruled out in the strongest conceivable way, along any possible path.

As in the finite-horizon case, we focus on GEI equilibria in which asset prices are deterministic, there is no risk premium, capital investment is identical across agents, and Assumption [2] holds. It is then straightforward to show that the vector $z_{t}=\left(a_{t}, C_{t}, W_{t}\right)$ satisfies the recursion $z_{t}=H\left(z_{t+1}\right)$ 
in every period. Furthermore, Assumption [2] implies that $a_{t}=1 /\left(1+\Pi_{t}\right)$ is bounded away from 0 .

Conversely, consider a sequence $\left\{z_{t}\right\}_{t=0}^{\infty}$ satisfying equilibrium recursion (15) and the condition $\inf _{t} a_{t}>0$. The perpetuity price $\Pi_{t}=1 / a_{t}-1$, the corresponding interest rate $R_{t}$ and the price sequence $\pi_{t}=\left(1 / R_{t}, 0, . .0\right)$ are bounded across $t$. By Lemma 4 , each agent has a unique optimal plan and markets clear in every date-event. This establishes

Proposition 4 Any sequence $\left\{z_{t}\right\}$ satisfying the condition $\inf _{t} a_{t}>0$ and the recursion $z_{t}=$ $H\left(z_{t+1}\right)$ defines a GEI equilibrium.

We henceforth focus on infinite horizon paths with these properties.

\subsection{Steady State}

A steady state is a fixed point of the recursion mapping $H$. By Assumption [2], the perpetuity has

a finite price $\Pi_{\infty}$ every period. The net interest rate $r_{\infty}$ is therefore positive, and the gross rate is larger than unity: $R_{\infty}=1+r_{\infty}>1$. Since storage has a lower rate of return $\left(\rho \leq 1<R_{\infty}\right)$, agents never allocate their savings to this low-yield technology: $S_{\infty}=0$. The marginal propensity to consume is given by $a_{\infty}=1-R_{\infty}^{-1}$. It is then easy to show

Proposition 5 In a steady state, the interest rate and capital stock satisfy

$$
\begin{aligned}
\ln \left(R_{\infty} \beta\right) & =-\Gamma^{2}\left(1-R_{\infty}^{-1}\right)^{2}\left[F\left(K_{\infty}\right)^{2} \sigma_{A}^{2}+K_{\infty}^{2} \sigma_{\delta}^{2}+\sigma_{e}^{2}\right] / 2 \\
R_{\infty} & =1-\delta+A F^{\prime}\left(K_{\infty}\right)-\Gamma\left(1-R_{\infty}^{-1}\right)\left[F^{\prime}\left(K_{\infty}\right) F\left(K_{\infty}\right) \sigma_{A}^{2}+K_{\infty} \sigma_{\delta}^{2}\right]
\end{aligned}
$$

The first equation corresponds to the stationary Euler condition for consumption, and the second to the optimality of capital investment. We note that $R_{\infty} \leq 1 / \beta$, and that the upper bound $1 / \beta$ is reached when markets are complete. This result is a possible solution to the low risk-free rate puzzle, as has been extensively discussed in the literature (e.g. Weil, 1992; Aiyagari, 1994; Constantinides and Duffie, 1996; Heaton and Lucas, 1996).

The closed-form system (18) - (19) allows us to conveniently analyze existence, multiplicity and comparative statics. We observe that equations (18) and (19) define two weakly decreasing functions $R_{1}(K)$ and $R_{2}(K)$, which intersect at a steady state. A continuity argument implies

Proposition 6 There exists a steady state in every infinite-horizon economy.

We now turn to comparative statics. As can be seen in equation (18), the idiosyncratic risks $\sigma_{e}, \sigma_{A}$ and $\sigma_{\delta}$ all increase the precautionary demand for savings, which tends to reduce the interest rate and increase capital investment. The capital stock $K_{\infty}$ therefore increases with the endowment 
risk $\sigma_{e}$, as in Aiyagari (1994). We note, however, that uninsurable technological shocks $\sigma_{A}$ and $\sigma_{\delta}$ also reduce the risk-adjusted return to investment and can thus discourage capital accumulation. While better insurance against endowment risk always reduces output through the precautionary effect, aggregate activity may actually be increased by new instruments for hedging technological risks. These conflicting effects lead in some cases to a non-monotonic relation between capital and idiosyncratic technological shocks, as can be checked numerically.

The steady state is unique when markets are complete, or more generally when agents are exposed only to uninsurable endowment shocks $\left(\sigma_{e} \geq 0, \sigma_{A}=\sigma_{\delta}=0\right) .{ }^{14}$ We prove this property by observing that Euler equation (18) is then independent of the capital stock and implies a unique real interest rate $R_{\infty}$. In the presence of productivity shocks, however, productive investment affects Euler equation (18). The functions $R_{1}(K)$ and $R_{2}(K)$ are then both strictly decreasing in $K$, and multiple steady states can arise. ${ }^{15}$

Proposition 7 There robustly exists a multiplicity of steady states in some economies with uninsurable production risks. In contrast, the steady state is unique in economies with either complete markets or only endowment risk.

While the wealth effects considered in earlier work (e.g. Banerjee and Newman, 1991; Galor and Zeira, 1993) play no role in our model, Proposition 7 shows that the interaction between the bond market and idiosyncratic production risk is a possible source of poverty traps. In an economy with a low capital stock $K_{\infty}$, agents have a weak precautionary motive and the equilibrium interest rate is high, as seen in (18). By investment equation (19), the low capital stock is also consistent with high marginal productivity and interest rate. The economy is thus stuck at a low wealth level as agents coordinate on a large real interest rate on the bond market.

The multiplicity of steady states can be viewed as a natural consequence of the dynamic complementarity in investment discussed in Section 3.2. When low investment $K_{\infty}$ and high interest rate $R_{\infty}$ are anticipated in future periods, investors are unwilling to make a large risky investment in the present. This implies in turn a high marginal productivity of capital, low precautionary savings and thus a high interest rate in the current period. This type of positive feedback naturally generates multiple equilibria, as has been emphasized in the literature on macroeconomic complementarities. Proposition 7 establishes that the complementarity between future and current investment can impact the number of steady states. It can also affect the local dynamics, as is now discussed.

\footnotetext{
${ }^{14}$ Note that the uniqueness of the steady state is specific to the the pure endowment version of our model. In general Bewley economies, multiple steady states can arise from the nonmonotonic impact of the interest rate on the aggregate demand for the bond (e.g. Aiyagari, 1994).

${ }^{15} \mathrm{It}$ is easy to show that the number of steady states is generically odd.
} 


\subsection{Local Dynamics}

The local dynamics around the steady state can be examined by linearizing the recursion mapping. Wealth $W_{t}$ is the only predetermined variable in the model, while consumption and marginal propensity are free to adjust. When markets are complete, the stable manifold has dimension 1 , the system is determined, and the economy converges monotonically to a unique steady state. None of these results need hold under incomplete markets.

We begin by considering economies with a single steady state.

Proposition 8 When the steady state is unique, it is either locally determined or locally undetermined depending on the economy's parameters.

We show this property by computing numerically the eigenvalues of the linearized system in some examples. A continuum of equilibria is obtained in an economy with patients agents (e.g. $\beta=$ 0.95) and large idiosyncratic production risk. Note that it is not easy to rule out this form of indeterminacy, because there is no obvious focal equilibrium on which agents can coordinate.

We provide in the Appendix an example of a supercritical flip bifurcation as $\sigma_{A}$ increases. This result is obtained in a class of economies with fixed psychological discount factor $\beta=0.95$. We infer that cycles of period 2 exist on an open set of economies.

\section{Proposition 9 Some economies robustly contain attracting cycles.}

These cycles arise with reasonably patient investors, but their existence appears to require high levels of idiosyncratic production risk.

Slightly different results are obtained in economies with only undiversifiable endowment risk $\left(\sigma_{e}>0, \sigma_{A}=\sigma_{\delta}=0\right)$. Let $\beta^{*}=1 / e \approx 0.368$. We show in the Appendix that the unique steady state is locally determined whenever the discount factor $\beta$ is larger than $\beta^{*}$. Uninsurable investment risk is thus indispensable to obtain indeterminacy and cycles with very patient agents. ${ }^{16}$ Consistent with the analysis of Section 3, these findings also suggest that idiosyncratic production shocks may help to generate cycles under less heavy discounting than is required in nonconvex complete-market growth economies (Boldrin and Montrucchio, 1986; Deneckere and Pelikan, 1986; Sorger, 1992).

We now examine economies with multiple steady states. The Appendix provides an example with three equilibria, in which the two extreme steady states (lowest and highest $W_{\infty}$ ) are locally unique and the middle one is totally unstable.

Proposition 10 When there are multiple steady states, some can be totally unstable.

\footnotetext{
${ }^{16}$ When $\beta \rightarrow 0$, indeterminacy and cycles are obtained in any economy with fixed production function $F$ and parameters $\Gamma, A, F, \delta, \rho, \sigma_{A}=\sigma_{\delta}=0, \sigma_{e}>0$. This result is consistent with the indeterminacy obtained in Calvet (2001) for exchange economies with sufficient impatience and large uninsurable endowment shocks.
} 
Several mechanisms help to explain the rich local properties uncovered in this subsection. First, idiosyncratic production risks induce a dynamic complementarity between future and current investment. Second, we showed in Section 3.3 that endogenous fluctuations can arise from a negative precautionary feedback between future and current wealth. While a precise decomposition is unavailable for our nonlinear system, we conjecture that both effects contribute to indeterminacy in infinite horizon economies. Intuition suggests that the negative feedback also helps to generate endogenous cycles, while complementarities in investment induce multiple steady states. We observe that uninsurable production risk is in any case crucial to obtain the negative feedback and dynamic complementarity, and thus the rich dynamics, along the infinite-horizon growth paths.

\section{Extensions}

We now show that our framework remains tractable under multiple capital types and sectors.

\subsection{Physical and Human Capital}

We consider a one-sector economy with two types of capital, and investigate the impact of specific idiosyncratic risks on investment and production efficiency. To simplify notation, the bond is the only traded asset and there is no exogenous endowment or storage. Let $k$ and $x$ respectively denote the stocks of physical and human capital. The output of agent $h$ is given by

$$
y_{t+1}^{h}=A_{t+1}^{h} F\left(k_{t}^{h}, x_{t}^{h}\right)+\left(1-\delta_{k, t+1}^{h}\right) k_{t}^{h}+\left(1-\delta_{x, t+1}^{h}\right) x_{t}^{h},
$$

where $\delta_{k, t+1}^{h}$ and $\delta_{x, t+1}^{h}$ are the stochastic depreciation rates on each capital type. The agent satisfies the budget constraints

$$
\begin{aligned}
& c_{t}^{h}+k_{t}^{h}+x_{t}^{h}+\theta_{t}^{h} / R_{t}=w_{t}^{h}, \\
& w_{t+1}^{h}=A_{t+1}^{h} F\left(k_{t}^{h}, x_{t}^{h}\right)+\left(1-\delta_{k, t+1}^{h}\right) k_{t}^{h}+\left(1-\delta_{x, t+1}^{h}\right) x_{t}^{h}+\theta_{t}^{h},
\end{aligned}
$$

where $\theta_{t}^{h}$ denotes bond holdings in period $t$.

Agents have identical CARA preferences and are exposed to idiosyncratic shocks

$$
\left(A_{t}^{h}, \delta_{k t}^{h}, \delta_{x t}^{h}\right) \sim \mathcal{N}(\mathbf{1}, \mathbf{\Sigma})
$$

where $\mathbf{1}=(1,1,1)^{\prime}$ and

$$
\boldsymbol{\Sigma}=\left[\begin{array}{ccc}
\sigma_{A}^{2} & 0 & 0 \\
0 & \sigma_{k}^{2} & 0 \\
0 & 0 & \sigma_{x}^{2}
\end{array}\right]
$$

The coefficient $\sigma_{A}$ specifies the idiosyncratic productivity risk common to both types of capital, whereas $\sigma_{k}$ and $\sigma_{x}$ quantify specific depreciation shocks. 
We focus on equilibrium paths along which capital investment is identical across agents and macroeconomic aggregates are deterministic. Risk-adjusted output is defined as:

$$
G(k, x, a) \equiv F(k, x)-\frac{\Gamma a}{2}\left[F(k, x)^{2} \sigma_{A}^{2}+k^{2} \sigma_{k}^{2}+x^{2} \sigma_{x}^{2}\right] .
$$

We easily check that the optimal individual decision $\left(K_{t}, X_{t}\right)$ maximizes $G\left(k, x, a_{t+1}\right)-R_{t}(k+x)$. The risk-adjusted returns to physical and human investment are therefore equated: $G_{k}=G_{x}=R_{t}$, implying

$$
F_{x}\left(K_{t}, X_{t}\right)-F_{k}\left(K_{t}, X_{t}\right)=\frac{\Gamma a_{t+1}\left(\sigma_{x}^{2} X_{t}-\sigma_{k}^{2} K_{t}\right)}{1-\Gamma a_{t+1} \sigma_{A}^{2} F\left(K_{t}, X_{t}\right)} .
$$

Undiversifiable depreciation risk can thus create a wedge between the marginal productivities of physical and human capital $\left(F_{k} \neq F_{x}\right)$. The allocation of savings is then inefficient, in the sense that decentralized production plans do not maximize aggregate output for a given level of savings:

$$
\left(K_{t}, X_{t}\right) \notin \arg \max _{(k, x)}\left\{F(k, x) \text { s.t. } k+x=K_{t}+X_{t}\right\} .
$$

To provide additional intuition, consider a Cobb-Douglas production function $F(k, x)=k^{\alpha} x^{\eta}$, where $\alpha>0, \eta>0$ and $\alpha+\eta<1$. The first-best (complete-market) allocation of savings is characterized by the relation $X_{t} / K_{t}=\eta / \alpha$. We can then show that under incomplete markets,

Proposition 11 If $\sigma_{k} / \sigma_{x} \neq \sqrt{\eta / \alpha}$, the equilibrium allocation of savings is inefficient:

$$
F\left(K_{t}, X_{t}\right)<\max _{(k, x)}\left\{F(k, x) \text { s.t. } k+x=K_{t}+X_{t}\right\} .
$$

In particular, $X_{t} / K_{t}<\eta / \alpha$ if and only if $\sigma_{k} / \sigma_{x}<\sqrt{\eta / \alpha}$.

The allocation of savings remains efficient under incomplete markets only if the type-specific risks are "balanced", in the sense that $\sigma_{k} / \sigma_{x}=\sqrt{\eta / \alpha}$. In an arbitrary economy, an increase in $\sigma_{k}$ generally shifts savings from physical to human capital. The effect on overall productivity then depends on the relative magnitude of depreciation risks. If $\sigma_{k} / \sigma_{x}<\sqrt{\eta / \alpha}$, an increase in $\sigma_{k}$ will actually increase investment efficiency and output for any level of savings, whereas an increase in $\sigma_{x}$ will decrease productivity.

This simple model of human capital thus confirms and extends the analysis conducted by Krebs (2003) in the context of endogenous growth. While Krebs considers only idiosyncratic shocks to human capital depreciation, our framework includes shocks to overall individual productivity and to the specific depreciation rates of each type of capital. This may be a useful extension, since the relative importance of undiversifiable shocks to human and physical capital remains an open empirical question. From a theoretical perspective, our model also suggests that capital-specific incompleteness may substantially influence the macroeconomic impact of financial innovation. 


\subsection{Multiple Sectors}

Our benchmark model easily extends to a neoclassical economy with a single good and multiple technologies $j \in\{1, \ldots, J\}$. As in the previous example, we simplify notation by assuming that the average depreciation rate is equal to unity, the endowment shock is zero, there is no storage, and the riskless bond is the only traded asset. When agent $h$ invests $k_{j, t}^{h}$ units in technology $j$ in period $t$, she obtains next period the random output

$$
y_{j, t+1}^{h}=A_{j, t+1}^{h} F_{j}\left(k_{j, t}^{h}\right),
$$

where $A_{j, t+1}^{h}$ is an idiosyncratic technology-specific shock and $F_{j}$ is a production function satisfying the Inada conditions. The budget constraints are then given by

$$
\begin{gathered}
c_{t}^{h}+\sum_{j=1}^{j} k_{t}^{h}+\theta_{t}^{h} / R_{t}=w_{t}^{h}, \\
w_{t+1}^{h}=\sum_{j=1}^{j} A_{j, t+1}^{h} F_{j}\left(k_{j, t}^{h}\right)+\theta_{t}^{h} .
\end{gathered}
$$

The shocks $\mathbf{A}_{t+1}^{h}=\left(A_{j, t+1}^{h}\right)_{j=1, \ldots, J}$ are jointly normal $\mathcal{N}(\mathbf{1}, \boldsymbol{\Sigma})$, where

$$
\boldsymbol{\Sigma}=\left[\begin{array}{ccc}
\sigma_{1}^{2} & \ldots & 0 \\
\vdots & \ddots & \vdots \\
0 & \ldots & \sigma_{J}^{2}
\end{array}\right]
$$

The coefficient $\sigma_{j} \geq 0$ measures idiosyncratic risk in sector $j .{ }^{17}$

Consider the risk-adjusted output of technology $j$ :

$$
G_{j}\left(k_{j}, a\right)=F_{j}\left(k_{j}\right)-\Gamma a F_{j}\left(k_{j}\right)^{2} \sigma_{j}^{2} / 2 .
$$

We easily show that the optimal capital stock $k_{j, t}^{h}$ maximizes $G_{j}\left(k, a_{t+1}\right)-R_{t} k$. The first-order condition is then

$$
\frac{\partial G_{j}}{\partial k}\left(K_{j, t}, a_{t+1}\right)=R_{t}
$$

Agents equate the interest rate with the risk-adjusted return to capital in every sector. As a result, the cross-sectoral allocation of capital does not maximize aggregate output given the level of savings.

Proposition 12 The allocation of capital is generically inefficient: for almost every $\boldsymbol{\Sigma}$, the individual plan $\left(K_{j, t}\right)_{1 \leq j \leq J}$ satisfies

$$
\sum_{j=1}^{J} F_{j}\left(K_{j, t}\right)<\max _{\left(k_{j}\right)}\left\{\sum_{j=1}^{J} F_{j}\left(k_{j}\right) \text { s.t. } \sum_{j=1}^{J} k_{j}=K_{t}\right\}
$$

where $K_{t}=\sum_{j=1}^{J} K_{j, t}$.

\footnotetext{
${ }^{17}$ For instance if $J=2, \sigma_{1}>0$ and $\sigma_{2}=0$, we can interpret sector 1 as private equity and sector 2 as public equity.
} 
As an example, let $F_{1}=F_{2}=\ldots=F_{J}$. Aggregate output is then maximized if and only if capital is allocated equally across sectors. This is obtained under incomplete markets if and only if $\sigma_{1}=\sigma_{2}=\ldots=\sigma_{J}$. If instead risks are asymmetric across sectors, the allocation of capital is biased towards the least risky sectors. In our benchmark one-sector model, incomplete markets induce lower income and savings because production risk discourages capital accumulation. With multiple sectors, the allocation of any given amount of capital is also inefficient and can further reduce aggregate output.

\section{Conclusion}

This paper investigates a missing market economy with decentralized production and idiosyncratic technological risk. Agents are unconstrained in their borrowing and lending, and incomplete risksharing is the only source of market imperfection. Macroeconomic aggregates and financial prices are deterministic but can follow complicated dynamics and cycles even when agents are very patient. The results illustrate that endowment and productivity shocks can have profoundly different implications for aggregate dynamics. Investment risk thus appears to be a promising new direction for business cycle research. In multisector settings, cyclical variations in sectoral risks may also lead to cyclical variations in the cross-sectoral allocation of resources and thus further amplify the business cycle. We leave the further examination of these issues for future research. 


\section{Appendix}

\section{Proof of Lemma 1}

We establish the lemma by a backward recursion. The results trivially hold at terminal date $T$. We now assume that the lemma has been proven for dates $t+1, t+2, \ldots, T$, and seek to show that it also holds at date $t$. An entrepreneur chooses consumption $c_{t}^{h}$, capital expenditure $k_{t}^{h}$, storage $s_{t}^{h}$ and asset holdings $\theta_{t}^{h}$ that maximize

$$
u\left(c_{t}^{h}\right)+\beta \mathbb{E}_{t} J\left[e_{t+1}^{h}+A_{t+1}^{h} F\left(k_{t}^{h}\right)+\left(1-\delta_{t+1}^{h}\right) k_{t}^{h}+\rho s_{t}^{h}+d_{t+1} \cdot \theta_{t}^{h}, t+1\right]
$$

subject to the budget equality $c_{t}^{h}+k_{t}^{h}+s_{t}^{h}+\pi_{t} \cdot \theta_{t}^{h}=w_{t}^{h}$, and the non-negativity constraints: $k_{t}^{h} \geq 0, s_{t}^{h} \geq 0$. The agent never uses storage if $R_{t}>\rho$, and is indifferent between investing in storage and investing in the bond if $R_{t}=\rho$. It is then convenient to consider $\widehat{\theta}_{0, t}^{h}=\rho s_{t}^{h}+\theta_{0, t}^{h}$.

The solution to the Bellman equation is simplified by the following observations. Since $w_{t+1}^{h}$ is normal, we rewrite the objective function as

$$
u\left(c_{t}^{h}\right)+\beta J\left[\Phi\left(k_{t}^{h}\right)+\widehat{\theta}_{0, t}^{h}-\frac{\Gamma a_{t+1}}{2} \operatorname{Var}_{t}\left(w_{t+1}^{h}\right), t+1\right] .
$$

Budget constraint (1) implies that $\widehat{\theta}_{0, t}^{h}=R_{t}\left(w_{t}^{h}-c_{t}^{h}-k_{t}^{h}-\sum_{n=1}^{N} \pi_{n, t} \theta_{n, t}^{h}\right)$. The decision problem thus reduces to maximizing

$$
u\left(c_{t}^{h}\right)+\beta J\left[\Phi\left(k_{t}^{h}\right)+R_{t}\left(w_{t}^{h}-c_{t}^{h}-k_{t}^{h}-\sum_{n=1}^{N} \pi_{n, t} \theta_{n, t}^{h}\right)-\frac{\Gamma a_{t+1}}{2} \operatorname{Var}_{t}\left(w_{t+1}^{h}\right) ; t+1\right] .
$$

over the unconstrained variables $\left(c_{t}^{h}, k_{t}^{h},\left(\theta_{n, t}^{h}\right)_{n=1}^{N}\right)$.

We begin by considering the demand for risky assets. Conditional on productive investment and consumption, the optimal portfolio maximizes

$$
-R_{t} \sum_{n=1}^{N} \pi_{n, t} \theta_{n, t}^{h}-\frac{\Gamma a_{t+1}}{2} \operatorname{Var}_{t}\left[e_{t+1}^{h}+A_{t+1}^{h} F\left(k_{t}^{h}\right)+\left(1-\delta_{t+1}^{h}\right) k_{t}^{h}+\sum_{n=1}^{N} \theta_{n, t}^{h} d_{n, t+1}\right] .
$$

The solution to this mean-variance problem is thus

$$
\theta_{n, t}^{h}=-\beta_{e, n}^{h, t}-\beta_{A, n}^{h, t} F\left(k_{t}^{h}\right)+\beta_{\delta, n}^{h, t} k_{t}^{h}-R_{t} \pi_{n, t} /\left(\Gamma a_{t+1}\right) .
$$

The agent fully hedges the endowment and productivity shocks, and takes a net position in risky assets to take advantage of possible risk premia. We plug asset holdings into (2) and infer that future wealth satisfies

$$
\begin{aligned}
w_{t+1}^{h}= & \Phi\left(k_{t}^{h}\right)+R_{t} \sum_{n=1}^{N} \pi_{n, t}\left[\beta_{A, n}^{h, t} F\left(k_{t}^{h}\right)-\beta_{\delta, n}^{h, t} k_{t}^{h}+\beta_{e, n}^{h, t}+\frac{R_{t} \pi_{n, t}}{\Gamma a_{t+1}}\right] \\
& +R_{t}\left(w_{t}^{h}-c_{t}^{h}-k_{t}^{h}\right)+F\left(k_{t}^{h}\right) \tilde{A}_{t+1}^{h}-\tilde{\delta}_{t+1}^{h} k_{t}^{h}+\tilde{e}_{t+1}^{h}-\frac{R_{t}}{\Gamma a_{t+1}} \sum_{n=1}^{N} \pi_{n, t} d_{n, t+1} .
\end{aligned}
$$


We now consider the optimal level of productive investment. Substitute next-period wealth (22) into the objective function:

$$
u\left(c_{t}^{h}\right)+\beta J\left[\begin{array}{c}
G\left(k_{t}^{h}, a_{t+1}, \sigma_{t+1}\right)+R_{t} \sum_{n=1}^{N} \pi_{n, t}\left[\beta_{A, n}^{h, t} F\left(k_{t}^{h}\right)-\beta_{\delta, n}^{h, t} k_{t}^{h}+\beta_{e, n}^{h, t}\right] \\
+R_{t}\left(w_{t}^{h}-c_{t}^{h}-k_{t}^{h}\right)+\frac{R_{t}^{2}}{2 \Gamma a_{t+1}} \sum_{n=1}^{N} \pi_{n, t}^{2}
\end{array} ; t+1\right] .
$$

The optimal level of productive investment therefore maximizes the criterion (6). Since $F^{\prime}(0)=$ $+\infty$, we infer that $k_{t}^{h}>0$ if $A+R_{t} \sum_{n=1}^{N} \beta_{A, n}^{h, t} \pi_{n, t}>0$.

We finally turn to optimal consumption. We differentiate equation (23), take logs and infer that consumption is a linear function of wealth: $c_{t}^{h}=a_{t} w_{t}^{h}+b_{t}^{h}$, with slope $a_{t}$ and intercept $b_{t}^{h}$ given by (3) and (4). The consumption-investment plan satisfies the Euler equation $u^{\prime}\left(c_{t}\right)=\beta R_{t} \mathbb{E}_{t} u^{\prime}\left(c_{t+1}\right)$. Since $u^{\prime}=-\Gamma u$, we infer that $u\left(c_{t}\right)=\beta R_{t} \mathbb{E}_{t} u\left(c_{t+1}\right)$. Hence $J^{h}(W, t) \equiv \mathbb{E}_{0} \sum_{s=t}^{T} \beta^{s} u\left(c_{s}\right)=(1+$ $\left.\Pi_{t}\right) u\left(c_{t}\right)$, or equivalently $J^{h}(W, t) \equiv-\left(\Gamma a_{t}\right)^{-1} \exp \left[-\Gamma\left(a_{t} W+b_{t}^{h}\right)\right]$. We conclude that the lemma holds in period $t$.

\section{Proof of Proposition 1}

We show the theorem by a backward recursion. At date $t=T$, agents have identical propensities $a_{T}=1$ and make no risky investment: $k_{T}^{h}=0$. Assume now that the properties of the theorem hold at instants $t+1, . ., T$. Step 1 shows that when there is only one type of technological risk, the risk premium is necessarily zero in any finite-horizon equilibrium. Step 2 derives the equilibrium conditions for all economies.

Step 1. Assume that agents are exposed to shocks to total productivity $A_{t+1}^{h}$ but not to the depreciation rate $\delta_{t+1}^{h}$. It is convenient to define the truncated price vector $\widehat{\pi}_{t}=\left(\pi_{n, t}\right)_{n=1}^{N}$ and the individual vectors $\beta_{A}^{h, t}=\left(\beta_{A, n}^{h, t}\right)_{n=1}^{N}$. Since there is no aggregate shock, we know that $\sum_{h=1}^{H} \beta_{A}^{h, t}=0$ and therefore $\sum_{h=1}^{H} \widehat{\pi}_{t} \cdot \beta_{A}^{h, t}=0$. Without loss of generality, we index households so that

$$
\widehat{\pi}_{t} \cdot \beta_{A}^{1, t} \geq \ldots \geq \widehat{\pi}_{t} \cdot \beta_{A}^{L, t} \geq 0 \geq \widehat{\pi}_{t} \cdot \beta_{A}^{L+1, t} \geq \ldots \geq \widehat{\pi}_{t} \cdot \beta_{A}^{H, t}
$$

The corresponding capital stocks provided by equation (6) then satisfy $k_{t}^{1} \geq \ldots \geq k_{t}^{H}$. For any $n \in\{1, . ., N\}$, the market clearing of security $n$ implies

$$
\frac{1}{H} \sum_{h=1}^{H} \theta_{n, t}^{h}=-\frac{1}{H} \sum_{h=1}^{H} F\left(k_{t}^{h}\right) \beta_{A, n}^{h, t}-\frac{R_{t} \pi_{n, t}}{\Gamma a_{t+1}}=0 .
$$

This yields the vector equality $\widehat{\pi}_{t}=-\Gamma a_{t+1} \sum_{h=1}^{H} F\left(k_{t}^{h}\right) \beta_{A}^{h, t} /\left(H R_{t}\right)$. Since

$$
\left\|\widehat{\pi}_{t}\right\|^{2}=-\frac{\Gamma a_{t+1}}{H R_{t}}\left[\sum_{h=1}^{L} F\left(k_{t}^{h}\right) \widehat{\pi}_{t} \cdot \beta_{A}^{h, t}+\sum_{h=L+1}^{H} F\left(k_{t}^{h}\right) \widehat{\pi}_{t} \cdot \beta_{A}^{h, t}\right],
$$


we infer $\left\|\widehat{\pi}_{t}\right\|^{2} \leq-\Gamma a_{t+1}\left[\sum_{h=1}^{L} F\left(k_{t}^{L}\right) \widehat{\pi}_{t} \cdot \beta_{A}^{h, t}+\sum_{h=L+1}^{H} F\left(k_{t}^{L+1}\right) \widehat{\pi}_{t} \cdot \beta_{A}^{h, t}\right] /\left(H R_{t}\right)$, or

$$
\left\|\widehat{\pi}_{t}\right\|^{2} \leq-\frac{\Gamma a_{t+1}}{H R_{t}}\left[F\left(k_{t}^{L}\right)-F\left(k_{t}^{L+1}\right)\right] \sum_{h=1}^{L} \widehat{\pi}_{t} \cdot \beta_{A}^{h, t} \leq 0 .
$$

We conclude that $\widehat{\pi}_{t}=0$ in any equilibrium. A similar argument holds if agents are only exposed to depreciation shocks $\delta_{t+1}^{h}$, but not to total productivity $A_{t+1}^{h}$.

Step 2. Agents make the same investment $k_{t}^{h}=K_{t}>0$ in the risky technology. Each agent purchases $\theta_{n, t}^{h}=-\beta_{e, n}^{h, t}-\beta_{A, n}^{h, t} F\left(K_{t}\right)+\beta_{\delta, n}^{h, t} K_{t}$ units of each risky asset; she thus sells at no cost the tradable components of her production and endowment risks. Equations (9) and (11) are implied by individual decision, and equations (10) and (13) are obtained by aggregating the budget constraints. The first-order condition $u^{\prime}\left(c_{t}^{h}\right)=\beta R_{t} \mathbb{E}_{t} u^{\prime}\left(c_{t+1}^{h}\right)$ implies

$$
0=c_{t}^{h}+\frac{\ln \left(\beta R_{t}\right)}{\Gamma}+\frac{1}{2} \Gamma a_{t+1}^{2}\left[F\left(K_{t}\right)^{2} \sigma_{A, t+1}^{2}+K_{t}^{2} \sigma_{\delta, t+1}^{2}+\sigma_{e, t+1}^{2}\right]-c_{t+1}^{h} .
$$

Aggregation of this relation then yields equation (12).

\section{Proof of Lemma 2}

The objective function $G\left(k, a_{t+1}, \sigma_{t+1}\right)-R_{t} k$ is conveniently rewritten as

$$
A F(k)+\left(1-\delta-R_{t}\right) k+e-\Gamma a_{t+1}\left[F(k)^{2} \sigma_{A, t+1}^{2}+k^{2} \sigma_{\delta, t+1}^{2}+\sigma_{e, t+1}^{2}\right] / 2 .
$$

The condition $F^{\prime}(0)=+\infty$ implies that the optimal capital stock is strictly positive.

Condition $(i)$. The objective function is strictly concave in $k$, and diverges to $-\infty$ as $k \rightarrow+\infty$. The optimal capital stock is finite, and FOC (14) has a unique solution.

Condition (ii). Since $R_{t} \geq \rho \geq 1-\delta$, the objective function (24) diverges to $-\infty$ as $k \rightarrow+\infty$, and the optimal capital stock is finite. Let $k_{0}=F^{-1}\left[A /\left(\Gamma a_{t+1} \sigma_{A}^{2}\right)\right]$. The function $G_{k}\left(k, a_{t+1}, \sigma_{t+1}\right)=$ $F^{\prime}(k)\left[A-\Gamma a_{t+1} F(k) \sigma_{A, t+1}^{2}\right]+1-\delta$ is decreasing and larger than $1-\delta$ when $k \in\left(0, k_{0}\right]$, and is strictly smaller than $1-\delta$ on $\left[k_{0},+\infty\right)$. We conclude that the equation $G_{k}\left(k, a_{t+1}, \sigma_{t+1}\right)=R_{t}$ has a unique solution.

\section{Proof of Lemma 3}

Let $K_{t}^{*}=\min \left\{k: G_{k}\left(k, a_{t+1}, \sigma_{t+1}\right)=\rho\right\}$ and $W_{t+1}^{*}=\Phi\left(K_{t}^{*}\right)$. Any solution $x_{t}$ can be calculated by following procedure. If $W_{t+1}<W_{t+1}^{*}$, equations (9) and (10) imply that $K_{t}=\Phi^{-1}\left(W_{t+1}\right), S_{t}=0$, and $R_{t}=G_{k}\left(K_{t}, a_{t+1}, \sigma_{t+1}\right)>\rho$. On the other hand if $W_{t+1} \geq W_{t+1}^{*}$, we infer from (9) and (10) 
that $R_{t}=\rho, K_{t}=K_{t}^{*}$, and $S_{t}=\left[W_{t+1}-\Phi\left(K_{t}\right)\right] / \rho$. Equations $(11)-(13)$ then assign unique values to $a_{t}, C_{t}$ and $W_{t}$. Finally, we observe that $\left(a_{t}, K_{t}, S_{t}, R_{t}\right) \in(0,1) \times \mathbb{R}_{+}^{*} \times \mathbb{R}_{+} \times[\rho,+\infty)$, while no simple restrictions seem to be imposed on current consumption and wealth.

\section{Proof of Proposition 2}

Consider $a \in \mathbb{R}$ and the mapping

$$
\varphi\left(W_{T}\right)= \begin{cases}W_{0}\left(W_{T}\right) & \text { if } W_{0}\left(W_{T}\right) \text { is defined and larger than } a \\ a & \text { otherwise }\end{cases}
$$

Since $\varphi$ is continuous on its domain $[e,+\infty)$, its image is an interval of the real line. When $W_{T} \rightarrow e$, productive investment $K_{T-1}$ and $S_{T-1}$ decline to zero, implying that $R_{T-1} \rightarrow+\infty, a_{T-1} \rightarrow 1$, $C_{T-1} \rightarrow-\infty, W_{T-1} \rightarrow-\infty$, and $\varphi(e)=a$. On the other hand when $W_{T} \rightarrow+\infty$, we observe that $R_{t}=\rho$ for all $t$ and $\varphi\left(W_{T}\right) \rightarrow+\infty$. This establishes that $\varphi[e,+\infty)=[a,+\infty)$. Since the argument applies to any choice of $a$, we conclude that $\varphi\left(W_{T}\right)=W_{0}$ has a solution for any $W_{0} \in \mathbb{R}$.

\section{Proof of Proposition 3}

Consider an economy with only undiversifiable endowment shocks $\left(\sigma_{e} \geq 0\right.$ and $\left.\sigma_{A}=\sigma_{\delta}=0\right)$. We establish the strict monotonicity of $W_{0}(\cdot)$ and thus equilibrium uniqueness by recursively showing the following

Property. The wealth function $W_{t}\left(W_{T}\right)$ is strictly increasing in $W_{T}$. Mean consumption $C_{t}\left(W_{T}\right)$, productive investment $K_{t}\left(K_{T}\right)$ and storage $S_{t}\left(S_{T}\right)$ are weakly increasing in $W_{T}$, while marginal propensity $a_{t}\left(W_{T}\right)$ and the interest rate $R_{t}\left(W_{T}\right)$ are weakly decreasing.

The statement is true for $t=T$. Assume that it is true for period $t$. In the absence of storage, the capital stock $K_{t-1}=\Phi^{-1}\left(W_{t}\right)$ locally increases with future wealth $W_{t}$ and thus terminal wealth $W_{T}$; the interest rate $R_{t-1}=\Phi^{\prime}\left(K_{t-1}\right)$ is decreasing in $K_{t-1}$ and thus in $W_{T}$. In the presence of storage, the safe investment $S_{t-1}$ locally increases in $W_{t}$ while $R_{t-1}$ and $K_{t-1}$ are locally constant. In either case, $K_{t-1}+S_{t-1}$ strictly increases with $W_{T}$. Since $a_{t}$ and $R_{t-1}$ are both decreasing in $W_{T}$, we infer that $a_{t-1}=1 /\left[1+\left(a_{t} R_{t-1}\right)^{-1}\right]$ is decreasing as well. Consumption

$$
C_{t-1}=C_{t}-\ln \left(\beta R_{t-1}\right) / \Gamma-\Gamma a_{t}^{2} \sigma_{e}^{2} / 2
$$

is therefore increasing in $W_{T}$. We conclude that $W_{t-1}=C_{t-1}+K_{t-1}+S_{t-1}$ strictly increases with the terminal wealth level $W_{T}$. 


\section{Proof of Lemma 4}

We begin by checking the convergence of the series (17) defining $b_{t}^{h}$. By Assumption [2], the sequences $\left\{a_{t}\right\}_{t=0}^{\infty}$ and $\left\{R_{t}\right\}_{t=0}^{\infty}$ are contained in compact intervals of the form $[\underline{a}, 1]$ and $[\underline{R}, \bar{R}]$, where $\underline{a}>0$ and $\underline{R}>0$. It follows that the sequences $\left\{k_{t}^{h}\right\}_{t=0}^{\infty}$ and $\left\{M_{t}^{h}\right\}_{t=0}^{\infty}$ are bounded. The deterministic sequence $\left\{b_{t}^{h}\right\}_{t=0}^{\infty}$ is thus well-defined and bounded.

We easily check that the consumption-investment plan defined by (7) satisfies the Euler equation $u^{\prime}\left(c_{t}\right)=\beta R_{t} \mathbb{E}_{t} u^{\prime}\left(c_{t+1}\right)$. Since $u^{\prime}=-\Gamma u$, we infer that $u\left(c_{t}\right)=\beta R_{t} \mathbb{E}_{t} u\left(c_{t+1}\right)$. The candidate plan thus generates utility $J^{h}(W, 0) \equiv \mathbb{E}_{0} \sum_{t=0}^{\infty} \beta^{t} u\left(c_{t}\right)=\left(1+\Pi_{0}\right) u\left(c_{0}\right)$, or equivalently $J^{h}(W, 0) \equiv$ $-\left(\Gamma a_{0}\right)^{-1} \exp \left[-\Gamma\left(a_{0} W+b_{0}^{h}\right)\right]$.

We must now verify that $J^{h}(W, 0)$ is indeed the value function. For a given $W$, consider an admissible plan $\left\{c_{t}^{\prime}, k_{t}^{\prime}, s_{t}^{\prime}, \theta_{t}^{\prime}, W_{t}^{\prime}\right\}_{t=0}^{\infty}$ that satisfies $W_{0}^{\prime}=W$ and the transversality condition $\lim _{T \rightarrow \infty} \beta^{T} \mathbb{E}_{0} u\left(W_{T}^{\prime}\right)=0$. We know that

$$
\begin{aligned}
J^{h}(W, 0) & =\underset{\{c, k, s, \theta, W\}}{\operatorname{Max}}\left[u(c)+\beta \mathbb{E}^{h}\left(W_{1}, 1\right)\right] \\
& \geq u\left(c_{0}^{\prime}\right)+\beta \mathbb{E}_{0} J^{h}\left(W_{1}^{\prime}, 1\right),
\end{aligned}
$$

and by repetition

$$
J^{h}(W, 0) \geq \mathbb{E}_{0}\left[\sum_{t=0}^{T-1} \beta^{t} u\left(c_{t}^{\prime}\right)\right]+\beta^{T} \mathbb{E}_{0} J^{h}\left(W_{T}^{\prime}, T\right) .
$$

Since $\left\{\exp \left(-\Gamma b_{T}^{h}\right) / a_{T}\right\}_{T=0}^{\infty}$ is bounded and $\exp \left(-\Gamma a_{T} W_{T}^{\prime}\right) \leq 1+\exp \left(-\Gamma W_{T}^{\prime}\right)$, the transversality

condition implies that $\beta^{T} \mathbb{E}_{0} J^{h}\left(W_{T}^{\prime}, T\right)=-\left(\Gamma a_{T}\right)^{-1} \beta^{T} \mathbb{E}_{0} \exp \left[-\Gamma\left(a_{T} W_{T}^{\prime}+b_{T}^{h}\right)\right]$ converges to 0 as $T \rightarrow \infty$. We thus obtain that

$$
J^{h}(W, 0) \geq \mathbb{E}_{0}\left[\sum_{t=0}^{+\infty} \beta^{t} u\left(c_{t}^{\prime}\right)\right]
$$

for any admissible strategy, and conclude that $J^{h}(W, 0)$ is the value function.

\section{Proof of Proposition 6}

Letting $\varphi(R) \equiv \Gamma^{-2}(1-1 / R)^{-2} \ln \left(\frac{1}{R \beta}\right)$, we rewrite system (18) - (19) as:

$$
\begin{gathered}
\varphi(R)=\left[F(K)^{2} \sigma_{A}^{2}+K^{2} \sigma_{\delta}^{2}+\sigma_{e}^{2}\right] / 2 \\
F^{\prime}(K)\left[A-\Gamma \sigma_{A}^{2}\left(1-\frac{1}{R}\right) F(K)\right]-\Gamma\left(1-\frac{1}{R}\right) K \sigma_{\delta}^{2}+1-\delta-R=0 .
\end{gathered}
$$

The function $\varphi(R)$ decreases on $(1,1 / \beta]$ and satisfies $\varphi(1,1 / \beta]=[0,+\infty)$. Equation $(27)$ thus defines the decreasing function $R_{1}(K)$, which maps $[0,+\infty)$ onto $\left(1, \varphi^{-1}\left(\sigma_{E}^{2} / 2\right)\right]$. Similarly, equation (28) implicitly defines the decreasing function $R_{2}(K)$ that maps $\left(0, K^{*}\right]$ onto $[1,+\infty)$, where $K^{*}=$ $\left(F^{\prime}\right)^{-1}(\delta / A)$. 
Consider the function $\Delta(K)=R_{1}(K)-R_{2}(K)$. When $K \rightarrow 0$, we observe that $R_{1}(K) \rightarrow$ $\varphi^{-1}\left(\sigma_{E}^{2} / 2\right), R_{2}(K) \rightarrow+\infty$, and therefore $\Delta(K) \rightarrow-\infty$. We also note that $\Delta\left(K^{*}\right)=R_{1}\left(K^{*}\right)-1>$ 0 . The graphs of the functions $R_{1}$ and $R_{2}$ therefore intersect and there exists at least one steady state.

Finally, we analyze the monotonicity of the steady state with respect to the economy's parameters. We consider the case $\left|R_{2}^{\prime}\left(K_{\infty}\right)\right|>\left|R_{1}^{\prime}\left(K_{\infty}\right)\right|$. An increase in $\sigma_{e}$ or $\beta$ pushes down the function $R_{1}(K)$ and leaves the function $R_{2}(K)$ unchanged. The steady state is therefore characterized by a lower interest rate and a higher capital stock. Similarly, an increase in $1-\delta$ and $A$ pushes up $R_{2}(K)$, also leading to a lower interest rate and a higher capital stock. We note that an increase in $\Gamma, \sigma_{A}$ or $\sigma_{\delta}$ pushes down both $R_{1}(K)$ and $R_{2}(K)$ and can have ambiguous effects, as is verified in simulations.

\section{Proof of Proposition 7}

It is enough to provide an example of multiplicity. We numerically check that there exist three equilibria when $\Gamma=1.2, A=20, \alpha=0.95, \beta=0.05, \delta=0.5, \sigma_{A}=9, \sigma_{\delta}=0, \sigma_{e}=0, e=0$.

\section{Local Dynamics around the Steady State}

There is no storage around the steady state. For computational simplicity, we focus on economies without undiversifiable depreciation risk. The iterated function $H$ is then implicitly defined by:

$$
\begin{aligned}
K_{t} & =\Phi^{-1}\left(W_{t+1}\right), \\
R_{t} & =F^{\prime}\left(K_{t}\right)\left[A-\Gamma a_{t+1} F\left(K_{t}\right) \sigma_{A}^{2}\right]+1-\delta, \\
a_{t} & =1 /\left[1+\left(a_{t+1} R_{t}\right)^{-1}\right], \\
C_{t} & =C_{t+1}-\ln \left(\beta R_{t}\right) / \Gamma-\Gamma a_{t+1}^{2}\left[F\left(K_{t}\right)^{2} \sigma_{A}^{2}+\sigma_{e}^{2}\right] / 2, \\
W_{t} & =C_{t}+K_{t} .
\end{aligned}
$$

The function $H$ has Jacobian matrix

$$
\partial H=\left[\begin{array}{ccc}
\frac{\partial a_{t}}{\partial a_{t+1}} & 0 & \frac{\partial a_{t}}{\partial W_{t+1}} \\
\frac{\partial C_{t}}{\partial a_{t+1}} & 1 & \frac{\partial C_{t}}{\partial W_{t+1}} \\
\frac{\partial C_{t}}{\partial a_{t+1}} & 1 & \frac{\partial\left(C_{t}+K_{t}\right)}{\partial W_{t+1}}
\end{array}\right] .
$$

We observe that $\partial K_{t} / \partial W_{t+1}=1 / \Phi^{\prime}\left(K_{t}\right)>0$, and ${ }^{18}$

$$
\begin{aligned}
\frac{\partial R_{t}}{\partial a_{t+1}} & =-\Gamma F\left(K_{t}\right) F^{\prime}\left(K_{t}\right) \sigma_{A}^{2} \leq 0, \\
\frac{\partial R_{t}}{\partial W_{t+1}} & =\frac{1}{\Phi^{\prime}\left(K_{t}\right)}\left\{F^{\prime \prime}\left(K_{t}\right)\left[A-\Gamma a_{t+1} F\left(K_{t}\right) \sigma_{A}^{2}\right]-a_{t+1}\left[F^{\prime}\left(K_{t}\right)\right]^{2} \Gamma \sigma_{A}^{2}\right\}<0 .
\end{aligned}
$$

\footnotetext{
${ }^{18}$ Since $R_{\infty}>1$, we infer that $A-\Gamma a_{t+1} F\left(K_{t}\right) \sigma_{A}^{2}>0$ on a neighborhood of the steady state.
} 
Let $\varphi(v)=1 /\left(1+v^{-1}\right)$. We note that $\varphi(v)=v /(1+v)$ and therefore $\varphi^{\prime}(v)=1 /(1+v)^{2}=[\varphi(v) / v]^{2}$. Since $a_{t}=\varphi\left(a_{t+1} R_{t}\right)$, we infer that

$$
\begin{aligned}
\frac{\partial a_{t}}{\partial a_{t+1}} & =\left(\frac{a_{t}}{a_{t+1} R_{t}}\right)^{2}\left(R_{t}-a_{t+1}\left|\frac{\partial R_{t}}{\partial a_{t+1}}\right|\right), \\
\frac{\partial a_{t}}{\partial W_{t+1}} & =-\left(\frac{a_{t}}{a_{t+1} R_{t}}\right)^{2} a_{t+1}\left|\frac{\partial R_{t}}{\partial W_{t+1}}\right|<0 .
\end{aligned}
$$

Future propensity $a_{t+1}$ has an ambiguous effect on current propensity $a_{t}$. There is both a positive direct effect (due to the complementarity of future and current consumption) and a negative indirect effect (the precautionary motive causes a decline in the current interest rate $R_{t}$ ). Since $C_{t}=$ $C_{t+1}-\ln \left(\beta R_{t}\right) / \Gamma-\Gamma a_{t+1}^{2}\left[F\left(K_{t}\right)^{2} \sigma_{A}^{2}+\sigma_{e}^{2}\right] / 2$, we infer that

$$
\begin{gathered}
\frac{\partial C_{t}}{\partial a_{t+1}}=\frac{1}{\Gamma R_{t}}\left|\frac{\partial R_{t}}{\partial a_{t+1}}\right|-\Gamma a_{t+1}\left[F\left(K_{t}\right)^{2} \sigma_{A}^{2}+\sigma_{e}^{2}\right] \\
\frac{\partial C_{t}}{\partial W_{t+1}}=\frac{1}{\Gamma R_{t}}\left|\frac{\partial R_{t}}{\partial W_{t+1}}\right|-\Gamma a_{t+1}^{2} \sigma_{A}^{2} \frac{F\left(K_{t}\right) F^{\prime}\left(K_{t}\right)}{\Phi^{\prime}\left(K_{t}\right)}
\end{gathered}
$$

An increase in $a_{t+1}$ and $W_{t+1}$ leads to a decline in the current interest rate, which has a positive effect on current consumption. On the other hand, the increase in $a_{t+1}$ and $W_{t+1}$ implies that the agent bears more risk between time $t$ and time $t+1$. The precautionary motive can then lead to a decrease in current consumption and current wealth, which may generate endogenous fluctuations.

The characteristic polynomial $P(x)=\operatorname{det}(\partial H-x I)$ can be rewritten as

$$
P(x)=\left(\frac{\partial a_{t}}{\partial a_{t+1}}-x\right)\left\{x^{2}-\left[1+\frac{\partial\left(C_{t}+K_{t}\right)}{\partial W_{t+1}}\right] x+\frac{\partial K_{t}}{\partial W_{t+1}}\right\}+x \frac{\partial C_{t}}{\partial a_{t+1}} \frac{\partial a_{t}}{\partial W_{t+1}} .
$$

The roots of $P$ are the eigenvalues of the backward dynamical system. Since $P(-\infty)=+\infty$ and $P(+\infty)=-\infty$, there always exists a real eigenvalue. Simple calculation shows that $P(1)>0$ if and only if $\left|R_{2}^{\prime}\left(K_{\infty}\right)\right|>\left|R_{1}^{\prime}\left(K_{\infty}\right)\right|$. Thus when there is a unique steady state, the Jacobian matrix $\partial H$ has an eigenvalue in $(1,+\infty)$, and the dimension of the stable manifold is at least 1 .

\section{A. Complete Markets}

We know that

$$
\frac{\partial a_{t}}{\partial a_{t+1}}=\beta, \frac{\partial C_{t}}{\partial a_{t+1}}=0, \frac{\partial C_{t}}{\partial W_{t+1}}>0,
$$

and the characteristic polynomial is of the form $P(x)=(\beta-x) Q(x)$, where

$$
Q(x)=x^{2}-\left[1+\frac{\partial\left(C_{t}+K_{t}\right)}{\partial W_{t+1}}\right] x+\frac{\partial K_{t}}{\partial W_{t+1}} .
$$

This implies that $x=\beta$ is an eigenvalue, which is contained in the interval $(0,1)$. We observe that $Q(0)>0$ and $Q(1)<0$, and infer the polynomial $Q$ has one root in the interval $(0,1)$ and one root 
in $(1,+\infty)$. Overall, the Jacobian matrix $\partial H$ has two eigenvalues in the interval $(0,1)$, and one eigenvalue larger than 1 . The stable manifold has thus dimension 1.

\section{B. Endowment Risk - No Productivity Shocks $\left(\sigma_{e}>0, \sigma_{A}=\sigma_{\delta}=0\right)$}

The unique steady state is defined by

$$
\begin{aligned}
\ln \left(R_{\infty} \beta\right) & =-\Gamma^{2}\left(1-R_{\infty}^{-1}\right)^{2} \sigma_{e}^{2} / 2 \\
R_{\infty} & =\Phi^{\prime}\left(K_{\infty}\right) .
\end{aligned}
$$

The characteristic polynomial simplifies to

$$
P(x)=\left(\frac{1}{R_{\infty}}-x\right)\left\{x^{2}-\left[1+\frac{1}{R_{\infty}}+\frac{A\left|F^{\prime \prime}\left(K_{\infty}\right)\right|}{\Gamma R_{\infty}^{2}}\right] x+\frac{1}{R_{\infty}}\right\}+x \frac{\Gamma a_{\infty}^{2}}{R_{\infty}^{3}} A\left|F^{\prime \prime}\left(K_{\infty}\right)\right| \sigma_{e}^{2} .
$$

We note that $P(1)>0$ and infer that the polynomial has at least one root $x_{1}$ in $(1,+\infty)$. It remains to characterize the other roots $x_{2}$ and $x_{3}$. It is useful to observe that $P(0)=R_{\infty}^{-2} \in(0,1)$.

If the roots $x_{2}$ and $x_{3}$ are complex, we know that $x_{3}=\bar{x}_{2}$. The relation $P(0)=x_{1}\left|x_{2}\right|^{2}<1$ implies that $\left|x_{2}\right|<1$. The economy is then stable and locally determined.

If the roots $x_{2}$ and $x_{3}$ are real, the inequalities $x_{1}>1$ and $x_{1} x_{2} x_{3}=P(0)>0$ implies that $x_{2}$ and $x_{3}$ have the same sign. Furthermore since $P(0)<1$, one of these roots is contained in the interval $(-1,1)$. We assume without loss of generality that $x_{2} \in(-1,1)$. We can then consider two cases:

- If $x_{2}$ and $x_{3}$ are both positive, the inequalities $P(0)>0$ and $P(1)>0$ imposes that $x_{2}, x_{3} \in$ $(0,1)$. The steady state is stable and locally determined.

- If on the other hand $x_{2}$ and $x_{3}$ are both negative, we know that $x_{3}>-1$ if and only if $P(-1)>0$. Since $\ln \left(R_{\infty} \beta\right)=-\Gamma^{2}\left(1-R_{\infty}^{-1}\right)^{2} \sigma_{e}^{2} / 2$ at the steady state, we easily infer

$$
P(-1)=2\left(\frac{1}{R_{\infty}}+1\right)^{2}+\frac{A\left|F^{\prime \prime}\left(K_{\infty}\right)\right|}{\Gamma R_{\infty}^{2}}\left[1+\frac{1}{R_{\infty}}+2 \frac{\ln \left(R_{\infty} \beta\right)}{R_{\infty}}\right] .
$$

The condition $R_{\infty} \in\left(1, \beta^{-1}\right]$ implies that

$$
P(-1) \geq 2\left(1+\frac{1}{R_{\infty}}\right)^{2}+\frac{2 A\left|F^{\prime \prime}\left(K_{\infty}\right)\right|}{\Gamma R_{\infty}^{2}}(1+\ln \beta) .
$$

Let $\beta^{*}=1 / e \approx 0.368$. Any economy with $\beta \geq \beta^{*}$ has a locally determined steady state. When agents only face uninsurable endowment shocks, it is thus impossible to obtain local indeterminacy and flip bifurcations with patient agents (i.e. with $\beta \geq \beta^{*}$ ).

Conversely, we can easily show that indeterminacy can arise in economies with sufficient impatience and large uninsurable shocks. When $\sigma_{e} \rightarrow+\infty$, the steady state satisfies $R_{\infty} \rightarrow 1$, 
$K_{\infty} \rightarrow\left(F^{\prime}\right)^{-1}(\delta / A)$ and $\Gamma^{2} a_{\infty}^{2} \sigma_{e}^{2} \rightarrow 2 \ln (1 / \beta)$. The characteristic polynomial is then

$$
P(-1) \sim 2\left[4+\frac{A\left|F^{\prime \prime}\left(K_{\infty}\right)\right|}{\Gamma}\left(1-\ln \frac{1}{\beta}\right)\right] .
$$

We infer that $P(-1)<0$ for a sufficiently low value of $\beta$. This result is consistent with the indeterminacy obtained in Calvet (2001) for exchange economies with sufficient impatience and large uninsurable endowment shocks.

\section{Uninsurable Productivity Shocks}

Consider the parameter values: $\beta=0.95, \Gamma=2, A=10, \alpha=0.35, \delta=0.1, \sigma_{\delta}=0, \sigma_{e}=0$. We check numerically that the steady state is unique and that the characteristic polynomial has one eigenvalue $x_{1}>1$ and two eigenvalues in the unit circle when $\sigma_{A} \leq 30.5$. On the other hand when $\sigma_{A}=31.5$, the steady state remains unique but there is one eigenvalue in each of the interval $(-\infty,-1),(-1,1)$ and $(1,+\infty)$. This establishes Proposition 8. We also note that the system undergoes a flip bifurcation as $\sigma_{A}$ varies between 30.5 and 31.5, which proves Proposition 9.

Finally, consider the economy $\Gamma=1.2, A=20, \alpha=0.95, \beta=0.05, \delta=0.5, \sigma_{A}=9, \sigma_{e}=0$, $\sigma_{\delta}=0, e=0$ examined in the proof of Proposition 7. This economy has three steady states, and it can be checked numerically that the steady state with the intermediate interest rate is totally unstable, thus establishing Proposition 10.

\section{Proof of Proposition 11}

We know that $G_{k}\left(K_{t}, X_{t}\right)=R_{t}$, we infer that $F_{x}\left(K_{t}, X_{t}\right)\left[1-\Gamma a_{t+1} \sigma_{A}^{2} F\left(K_{t}, X_{t}\right)\right]=R_{t}+\Gamma a_{t+1} \sigma_{x}^{2} X_{t}$, which implies

$$
1-\Gamma a_{t+1} \sigma_{A}^{2} F\left(K_{t}, X_{t}\right)>0
$$

Equation (20) can be rewritten as

$$
K_{t}^{\alpha} X_{t}^{\eta}\left(\frac{\eta}{X_{t}}-\frac{\alpha}{K_{t}}\right)=\left(\sigma_{x}^{2} X_{t}-\sigma_{k}^{2} K_{t}\right) \frac{\Gamma a_{t+1}}{1-\Gamma a_{t+1} \sigma_{A}^{2} F\left(K_{t}, X_{t}\right)}
$$

We consider parameters satisfying $\sigma_{k} / \sigma_{x}<\sqrt{\eta / \alpha}$, and assume that $X_{t} / K_{t} \geq \eta / \alpha$. The left-hand side of (31) is weakly negative. On the other hand since $X_{t} / K_{t} \geq \eta / \alpha>\sigma_{k}^{2} / \sigma_{x}^{2}$, the right-hand side of (31) is strictly positive - a contradiction. We conclude that $X_{t} / K_{t}<\eta / \alpha$.

\section{Proof of Proposition 12}

The proposition is a direct application of Sard's theorem. We assume for notational simplicity that there are two sectors $(J=2)$. For a given sequence $\left\{R_{t}\right\}_{t=0}^{\infty}$, consider the function

$$
H\left(k_{1}, k_{2} ; \sigma_{1}, \sigma_{2}\right)=\left[\frac{\partial G_{1}}{\partial k}\left(k_{1}, \sigma_{1}\right)-R_{t} ; \frac{\partial G_{2}}{\partial k}\left(k_{2}, \sigma_{2}\right)-R_{t} ; F_{1}^{\prime}\left(k_{1}\right)-F_{2}^{\prime}\left(k_{2}\right)\right] \text {. }
$$


It is easy to check that the Jacobian matrix of $H$ has rank 3 whenever $H\left(k_{1}, k_{2} ; \sigma_{1}, \sigma_{2}\right)=0$. We conclude that the system $H=0$ has no solution for almost every choice of $\left(\sigma_{1}, \sigma_{2}\right)$.

\section{References}

Aghion, P., Bacchetta, P., Banerjee, A., 2000. "Capital Markets and the Instability of Open Economies," manuscript, Harvard University.

Aghion, P., Banerjee, A., Piketty, T., 1999. Dualism and Macroeconomic Activity. Quarterly Journal of Economics 114, 1359-1397.

Aiyagari, S. R., 1994. Uninsured Idiosyncratic Risk and Aggregate Saving. Quarterly Journal of Economics 109, 659-684.

Angeletos, G. M., Calvet, L. E., 2003. "Idiosyncratic Production Risk, Growth and the Business Cycle." NBER Working Paper 9764. Forthcoming in Journal of Monetary Economics.

Banerjee, A., and Newman, A., 1991. Risk-Bearing and the Theory of Income Distribution. Review of Economic Studies 58, 211-235.

Benhabib, J., Day, R., 1982. A Characterization of Erratic Dynamics in the Overlapping Generations Model. Journal of Economic Dynamics and Control 4, 37-55.

Benhabib, J., Farmer, R., 1994. Indeterminacy and Increasing Returns. Journal of Economic Theory 63, $19-41$.

Benhabib, J., Nishimura, K., 1979. The Hopf Bifurcation and the Existence and Stability of Closed Orbits in Multisector Models of Optimal Economic Growth. Journal of Economic Theory 21, 421-444.

Boldrin, M., Montrucchio, L., 1986. On the Indeterminacy of Capital Accumulation Paths. Journal of Economic Theory 40, 26-39.

Brock, W., Mirman, L., 1972. Optimal Economic Growth and Uncertainty: The Discounted Case. Journal of Economic Theory 4, 497-513.

Caballero, R., 1990. Consumption Puzzles and Precautionary Saving. Journal of Monetary Economics 25, 113-136.

Calvet, L. E., 2001. Incomplete Markets and Volatility. Journal of Economic Theory 98, 295-338.

Cass, D., 1965. Optimum Growth in an Aggregative Model of Capital Accumulation. Review of Economic Studies 32, 233-240. 
Constantinides, G., Duffie, D., 1996. Asset Pricing with Heterogeneous Consumers. Journal of Political Economy 104, 219-240.

Deneckere, R., Pelikan, S., 1986. Competitive Chaos. Journal of Economic Theory 40, 13-25.

Galor, O., Zeira, J., 1993. Income Distribution and Macroeconomics. Review of Economic Studies 60, 35-52.

Grandmont, J. M., 1985. On Endogenous Competitive Business Cycles. Econometrica 53, 995-1045.

Heaton, J., Lucas, D. J., 1996. Evaluating the Effects of Incomplete Markets on Risk Sharing and Asset Pricing. Journal of Political Economy 104, 443-487.

Huggett, M., 1997. The One-Sector Growth Model with Idiosyncratic Shocks: Steady States and Dynamics. Journal of Monetary Economics 39, 385-403.

Kiyotaki, N., Moore, J., 1997. Credit Cycles. Journal of Political Economy 105, 211-248.

Koopmans, T. C., 1965. On the Concept of Optimal Economic Growth, in: The Economic Approach to Development Planning (North-Holland, Amsterdam).

Krebs, T., 2003. Human Capital Risk and Economic Growth. Quarterly Journal of Economics 118, 709-744.

Krusell, P., Smith, A., 1998. Income and Wealth Heterogeneity in the Macroeconomy. Journal of Political Economy 106, 867-896.

Leland, H., 1968. Saving and Uncertainty: The Precautionary Demand for Saving. Quarterly Journal of Economics 82, 465-473.

Ljungqvist, L., Sargent, T. J., 2000. Recursive Macroeconomic Theory. MIT Press.

Mankiw, N. G., 1986. The Equity Premium and the Concentration of Aggregate Shocks. Journal of Financial Economics 17, 211-219.

Marcet, A., Obiols-Hom, F., Weil, P., 2000. Incomplete Markets, Labor Supply and Capital Accumulation. Working Paper, Universitat Pompeu-Fabra.

Mitra, T., 1996. An Exact Discount Factor Restriction for Period-Three Cycles in Dynamic Optimization Models. Journal of Economic Theory 69, 281-305.

Nishimura, K., Yano, M., 1996. On the Least Upper Bound of Discount Factors That Are Compatible with Optimal Period-Three Cycles. Journal of Economic Theory 69, 306-333.

Sandmo, A., 1970. The Effect of Uncertainty on Saving Decisions. Review of Economic Studies 37, 353-360.

Sorger, G., 1992. On the Minimum Rate of Impatience for Complicated Optimal Growth Paths. Journal of Economic Theory 56, 160-179.

Weil, P., 1992. Equilibrium Asset Prices in Economies with Undiversifiable Labor Income Risk. Journal of Economic Dynamics and Control 16, 769-790. 


\section{Figure 1A. Finite-Horizon Growth Path}
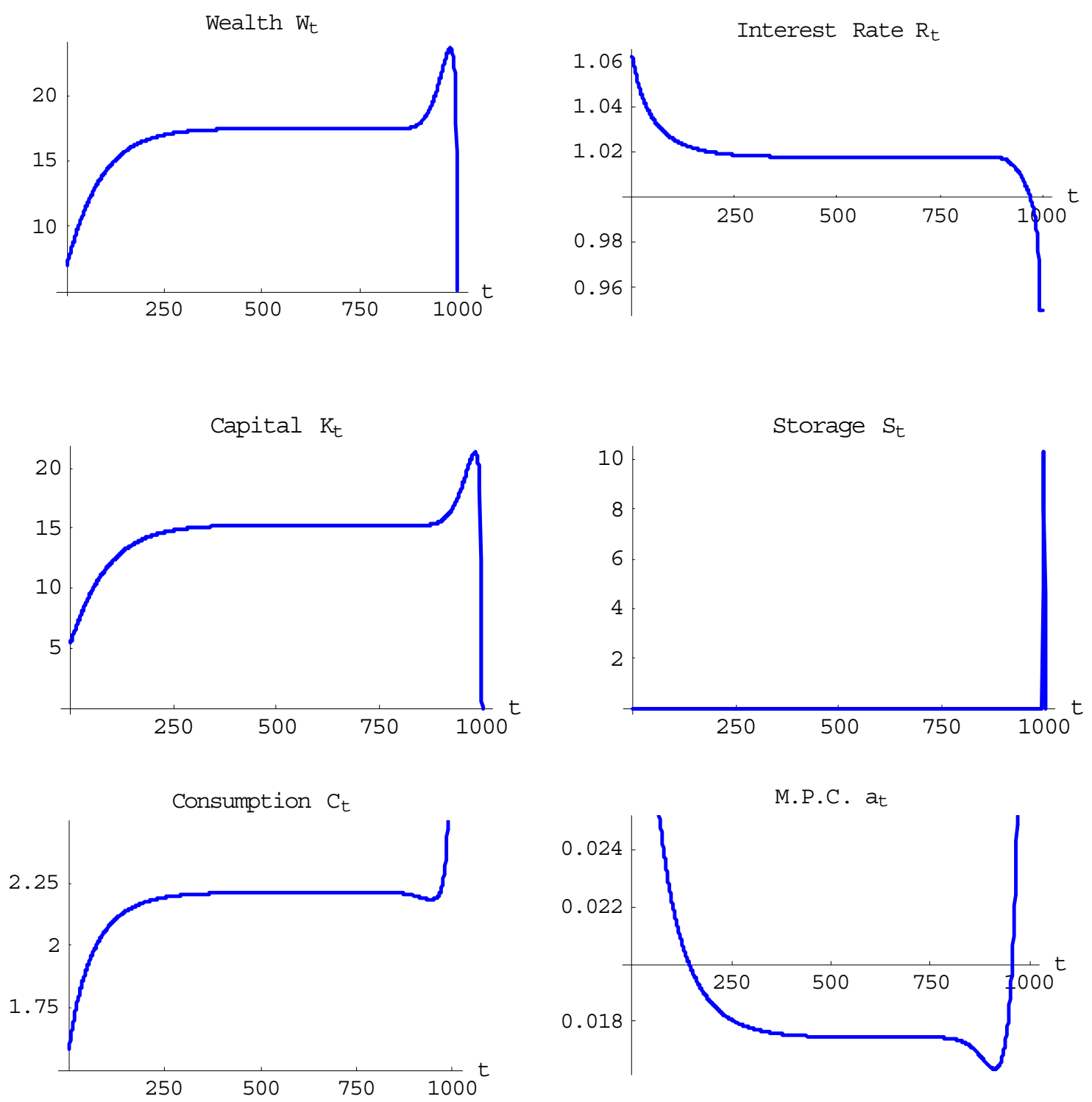

We plot the time paths of wealth, interest rate, capital, storage, consumption and marginal propensity to consume for a finite-horizon economy $(T=1000)$ with uninsurable idiosyncratic production risk $\left(\sigma_{\mathrm{A}}>0\right)$. 


\section{Figure 1B. Turnpike Property}

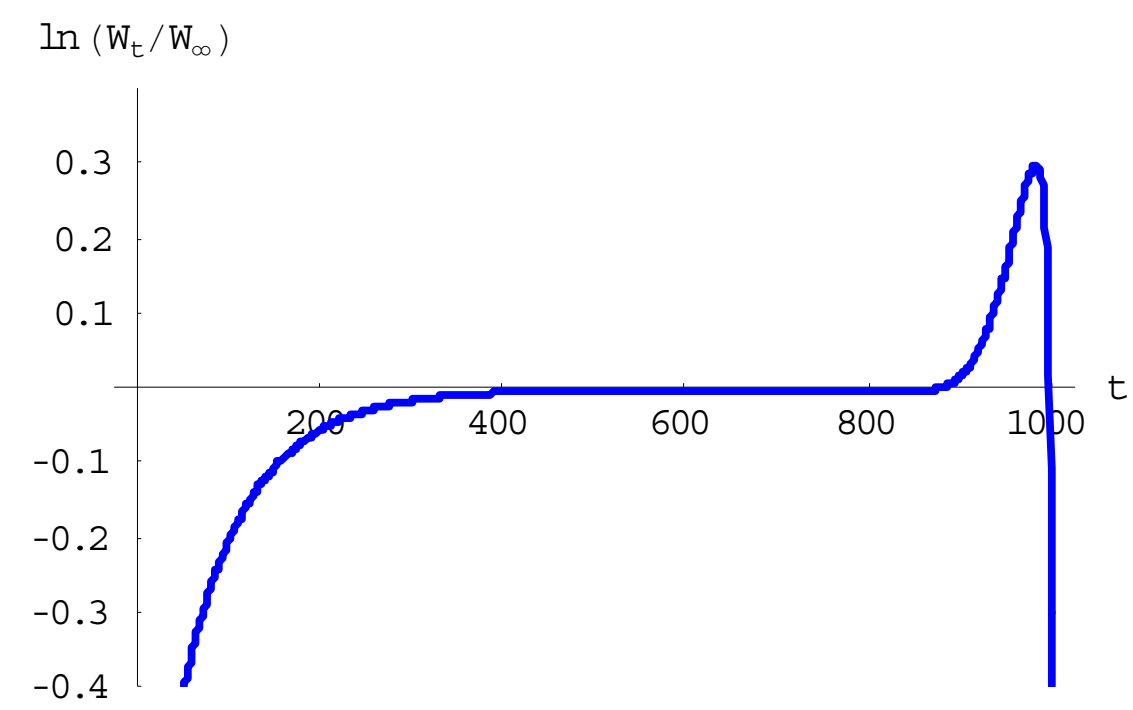

The figure plots $\ln \left(W_{t} / W_{\infty}\right)$, which quantifies the distance between the wealth $W_{t}$ in period $t$ of a finite-horizon economy $(T=1000)$ and the steady-state level of wealth $W_{\infty}$ under infinite horizon $(T=\infty)$. The economy is the same as in Figure 1A. 


\section{Figure 2. Nonmonotonicity of $\mathrm{W}_{0}\left(\mathrm{~W}_{\mathrm{T}}\right)$}

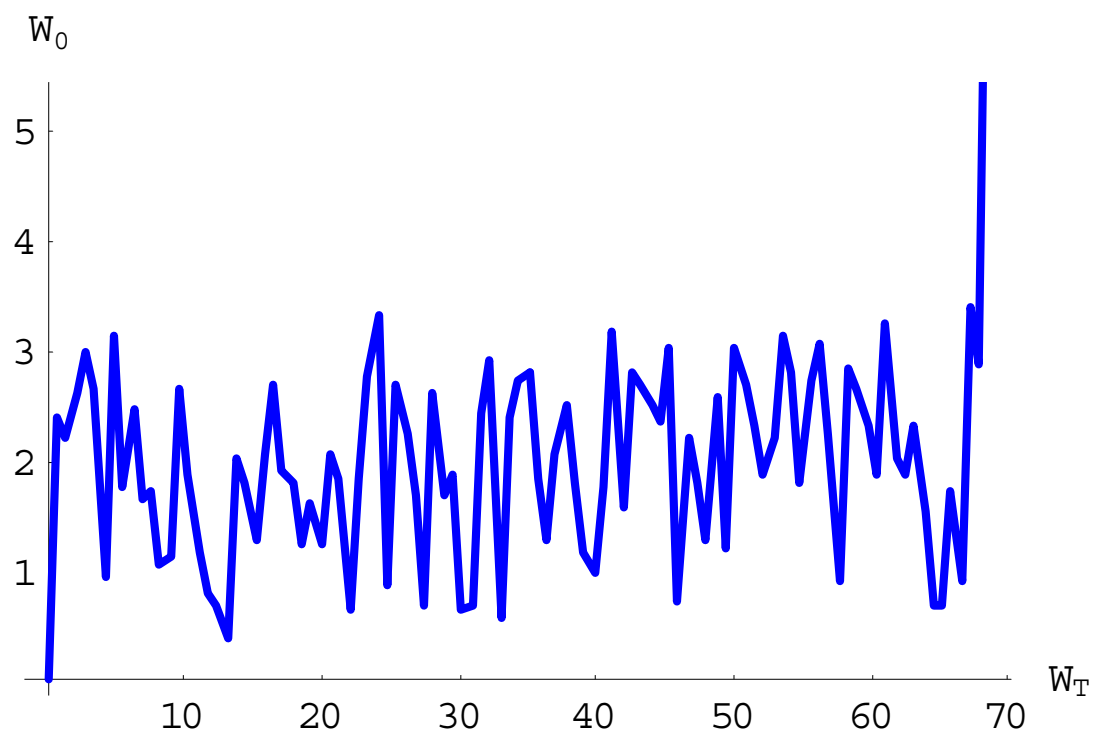

Multiple equilibria in a finite-horizon economy with idiosyncratic production risk and patient agents $(\beta=0.9)$. The figure illustrates the non-monotonic relation between initial and final wealth. For any given $W_{0} \in[1,3]$, there are multiple $W_{T}$ corresponding to different equilibrium paths. 
Figure 3. Endogenous Fluctuations in Finite Horizon
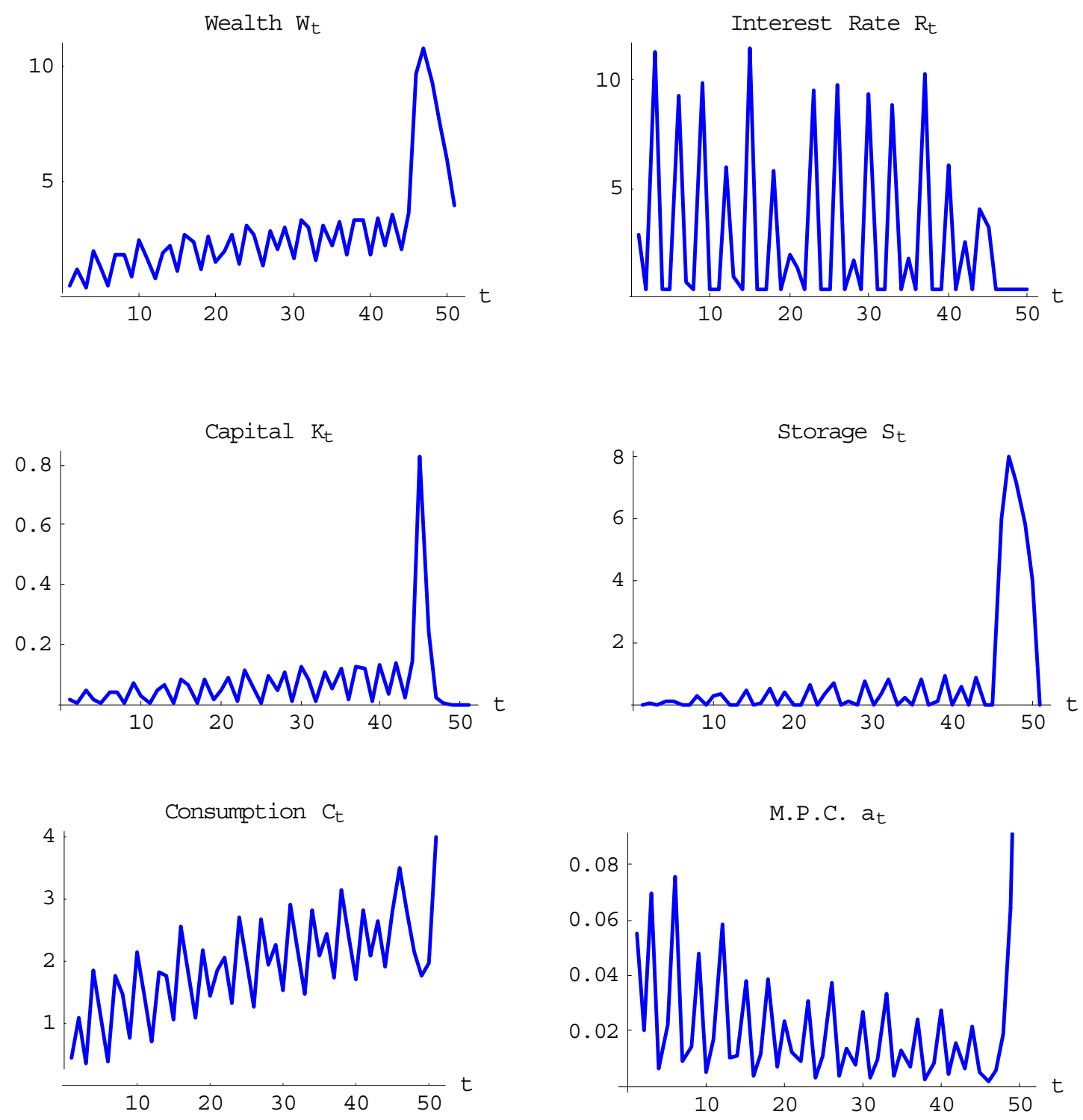

We plot the time paths of aggregate wealth, interest rate, capital investment, storage, consumption, and marginal propensity to consume in a finite-horizon economy with idiosyncratic production risk and patient agents $(\beta=0.99)$. 